\title{
Modelling the continuous exchange of nitrogen between microbial decomposers, the organs and symbionts of plants, soil reserves and the atmosphere
}

\author{
Marc Pansu $^{\mathrm{a}, *}$, Hatem Ibrahim ${ }^{\mathrm{a}, \mathrm{b}}$, Abdessatar Hatira $^{\mathrm{b}}$, Nadhem Brahim ${ }^{\mathrm{b}}$, Jean-Jacques Drevon ${ }^{\mathrm{c}}$, \\ Jean-Michel Harmand ${ }^{\mathrm{d}}$, Jean-Luc Chotte ${ }^{\mathrm{a}}$, Didier Blavet ${ }^{\mathrm{a}}$

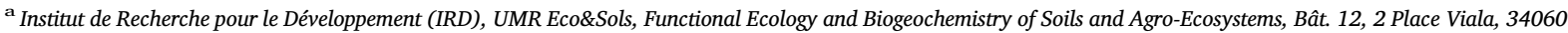 \\ Montpellier Cedex 2, France \\ ${ }^{\mathrm{b}}$ U.R. 04/UR/10-02 Pedology, Department of Geology, Faculty of Sciences of Tunis, El Manar University, 2092 Tunis, Tunisia \\ ${ }^{\mathrm{c}}$ Institut National de la Recherche Agronomique (INRA), UMR Eco\&Sols, Bât. 12, 2 Place Viala, 34060 Montpellier Cedex 2, France \\ d Centre de Coopération Internationale en Recherche Agronomique pour le Développement (CIRAD), UMR Eco\&Sols, Functional Ecology and Biogeochemistry of Soils and \\ Agro-Ecosystems, Bât. 12, 2 Place Viala, 34060 Montpellier Cedex 2, France
}

\section{A R T I C L E I N F O}

\section{Keywords:}

Nitrogen cycle

$\mathrm{N}$ microbial exchanges

$\mathrm{N}$ fixation

$\mathrm{C}$ and $\mathrm{N}$ modelling

Agro-ecology

Global change

\begin{abstract}
A B S T R A C T
Most of the $\mathrm{C}$ and $\mathrm{N}$ models published over past decades are based on parameters not always linked to the environment and underestimate the role of microorganisms. They are often over-parameterized, which can give multiple solutions for flow calculations between state variables. This work proposes a modelling method centred on the functioning of living organisms in order to calculate flow parameters using data on $\mathrm{N}$ stocks in decomposers, plant organs, symbiotic microorganisms, and the soil compartments. The model was settled via a complex $\mathrm{N}$ fixing and intercropping system of durum wheat/faba bean compared to the cropping of pure durum wheat and pure faba bean, all in the context of organic farming invaded by weeds and weeded by hand just before flowering. To avoid perturbation of natural exchanges of C and N, no fertilizer was added from 1997 to 2011.

The equation system defined for the association of any number of plants, as well as parameters previously published for C-flow calculations were used, and only a few parameters specific to $\mathrm{N}$ flows were added, and are discussed. The results showed the strong link between $\mathrm{N}$ and $\mathrm{C}$ in the environment. The calculations converge toward an unique set of solutions that is consistent with literature data when available. The labile organic $\mathrm{N}$ of microbial origin was modelled as the main potentially available stock. Living microorganisms stored about $1 \%$ of total $\mathrm{N}$, which was close to the $\mathrm{N}$ stock in faba bean and four times more than stock in durum wheat. Inorganic $\mathrm{N}$ was immobilized before flowering in competition with $\mathrm{N}$ requirement of durum wheat roots. Net $\mathrm{N}$ mineralization, mainly from decomposition of faba bean roots, started too late to improve wheat production. During the cropping period, weeds accounted for losses of $20 \mathrm{~kg} \mathrm{Nha}^{-1}$, while the atmospheric $\mathrm{N}_{2}$ fixation of $90 \mathrm{~kg} \mathrm{~N} \mathrm{ha}^{-1}$ was close to the total microbial immobilization. The model associating microbial and plant flows of $\mathrm{C}$ and $\mathrm{N}$ in complex plant covers, appears as a robust tool to quantify the exchanges of the earth organisms with the soil and atmosphere. It enables to propose essential recommendations to improve as well agro-ecology as predictions of global changes of $\mathrm{C}$ and $\mathrm{N}$ stocks.
\end{abstract}

\section{Introduction}

Although named Azote by Lavoisier, which means lifeless because inert in gaseous form compared to oxygen, this atmospheric element is probably better named nitrogen $(\mathrm{N})$ in its multiple ionic and organic forms essential to life. It undergoes many transformations of very variable kinetics, inside and outside the soil in the nitrogen cycle
(Jetten, 2008), current models of crop production like Ceres (Ritchie and Otter, 1984), Epic (Williams et al., 1989) or Stics (Brisson et al., 1998) integrate management of $\mathrm{N}$ conjointly with that of carbon (C) and water. Living plants store a weak part of the global $\mathrm{N}$ stock mainly by absorption of mineral $\mathrm{N}$ by roots, especially nitrates (Inselsbacher et al., 2013), and fixation of atmospheric $\mathrm{N}_{2}$ by bacterial biosynthesis of ammonium (Unkovich and Baldock, 2008). Nevertheless, there is much

\footnotetext{
* Corresponding author.

E-mail address: marc.pansu@ird.fr (M. Pansu).
} 
less inorganic $\mathrm{N}$ available for plant growth than the organic $\mathrm{N}$ linked to $\mathrm{C}$ forms produced by plants and microbial decomposers (Lin et al., 2000; Pansu and Gautheyrou, 2006). This underlines the complexity of the $\mathrm{N}$ cycle and the need of models describing precisely the $\mathrm{N}$ mineralization and immobilization processes linked to evolutions of the microbial biomass and organic substrates. Indeed, the numerous $\mathrm{N}$ models reviewed by Manzoni and Porporato (2009) are not always linked to C, sometimes poorly mechanistic and not really centred on the functional ecology of the plant-microbe systems. For Pansu et al. (2009) the published models were over parameterized, two third of them needed parameters not linked to environmental variables, one third did not use explicitly a microbial compartment and none of them considered really the functional role of microorganisms. A new generation was often awaited to connect more deeply the $\mathrm{C}$ and $\mathrm{N}$ cycles (Gärdenäs et al., 2011), to really express the direct microbial control over decomposition and N exchanges (Blagodatsky et al., 2010; Todd-Brown et al., 2012) possibly at the cellular scale (Gras et al., 2011), if necessary to bridge the gap between linear models and laws of microbial growth (Neill and Gignoux, 2006) and generally to consider more deeply the role of microorganisms in a new green revolution.

Using isotopic data collected from various ecosystems, Pansu et al. (2014) proposed to link the $\mathrm{N}$ and $\mathrm{C}$ cycles to the functional ecology of soil microbial biomass defined by the MOMOS model (Pansu et al., 2010) parameterized only by 7 kinetic constant all linked to climate, and some of them to soil physical properties and quality of organic inputs. They compared two assumptions (i) microbial homeostasis (constant C:N ratio of soil microorganisms) to reduce the model complexity and the risks of over-parameterization, and (ii) variable microbial C:N ratio to take account of a succession of decomposer communities (Wu et al., 2012) and their diversity (Philippot et al., 2013). The results showed that homeostasis was not always an acceptable hypothesis but could be considered as a valid approximation, especially in hot, well-drained plain areas (Pansu et al., 2014) where prokaryotes are particularly active, confirming the MOMOS expectation to predict the functional ecology of these soil microbial communities (Sikorski, 2015).

Microorganisms representing the largest part of the earth life need plant substrates as C sources with large research questions about the competition or the synergy with plants for the $\mathrm{N}$ nutrients (van der Heijden et al., 2008). Corre-Hellou et al. (2009) have modelled crop growth and $\mathrm{N}$ accumulation in pea-barley intercrops. Jensen et al. (2010) reported substantial savings of $\mathrm{N}$ fertilizer by symbiotic fixation of faba bean cropping systems and the need to increase associated knowledges about the $\mathrm{N}$ exchanges between roots and microorganisms. Ibrahim et al. (2016) have used the Momos model, coupled with a soil water model and a plant production module, to simulate the continuous exchanges of $\mathrm{C}$ in intercropping of durum wheat and faba bean. This has allowed for example to estimate separately root tissue respirations and microbial respiration as attempted by Morell et al. (2012) with the Motor model (Verberne et al., 1990). This paper aims to extend the study of Ibrahim et al. (2016) to the continuous N exchanges between the same living organisms, the soil and the atmosphere. The objective was to test the equation system as a new tool to simulate the $\mathrm{N}$ exchange flows using measurements of state variables available in the field experiment of Ibrahim et al. (2016). For a model not over parameterized, the values of the flow parameters must converge to a unique set of solutions independently of the set of initial values. The inputs of $\mathrm{N}$ to microorganisms can be calculated from MOMOS-C simulation of the death of each organ and symbiont of each plant (Ibrahim et al., 2016) divided by its corresponding C-to-N ratio (which can be available in data bases). The modelling method should enable to estimate threshold values of microbial C-to-N ratio regulating immobilization or mineralization of inorganic $\mathrm{N}$ from decomposer microorganisms. And simultaneously to estimate essential parameters of $\mathrm{N}$ exchanges for plant growth: time functions of absorption of inorganic $\mathrm{N}$ by roots, $\mathrm{N}$ fixation by symbiosis, $\mathrm{N}$ transfers to roots, shoots, grains, and $\mathrm{N}$ losses in environment. Such estimations complementary to that of Ibrahim et al. (2016) must help to clarify essential points of ecosystem functioning such as: (i) how do decomposer organisms affect $\mathrm{N}$ accessibility or depletion for plant roots, is microbial homeostasis a valid assumption to control $\mathrm{N}$ exchanges in the legume-cereal system? (ii) how do the $\mathrm{N}$ exchanges between living organisms affect flows of photosynthesised $\mathrm{C}$ and crop yields? How can the $\mathrm{N}$ use by cereal roots be improved by atmospheric fixation of legume symbionts?

More generally, this paper aims to propose two finalities: (i) a methodology to understand and improve the $\mathrm{C}$ and $\mathrm{N}$ exchanges and the resulting yields whatever are the crops and the number of plants in interaction, (ii) a tool to model the exchanges of $\mathrm{C}$ and $\mathrm{N}$ at larger scales, highlighting the data bases which have to be collected from literature, approximations, or experiments analogous to that of this paper.

\section{Materials and methods}

\subsection{Field experiment and data collection}

The field experiment and soil were described in detail by Ibrahim et al. (2016). The soil was a loamy chromic Cambisol with an alkaline $\mathrm{pH}$ of 8.2 which greatly differentiate it from the tropical soils of model calibration and validation. This experiment was carried out at the Institut National de la Recherche Agronomique (INRA) Mediterranean station of Mauguio $\left(43^{\circ} 37^{\prime} 12.60^{\prime \prime} \mathrm{N} / 3^{\circ} 59^{\prime} 07.12^{\prime \prime} \mathrm{E}\right){ }^{1}$ France. Plots of $6 \mathrm{~m} \times 10 \mathrm{~m}$ were cultivated with three crop systems (four field replicates) using organic farming methods applied since 1997 without any fertilizer addition (1) durum wheat (Triticum durum Desf. c.v. LA1823) monocrop at a density of $100 \pm 23$ plants $\mathrm{m}^{-2}$ (2) faba bean (Vicia faba L. c.v. "Castel") monocrop at a density of $17 \pm 7$ plants $\mathrm{m}^{-2}$, and (3) durum wheat LA1823 - faba bean Castel intercrop at a density of $72 \pm 28$ durum wheat $\mathrm{m}^{-2}$ and $16 \pm 6$ faba bean plants $\mathrm{m}^{-2}$. The low fertility allowed only these low plant densities but gave optimal conditions to quantify natural exchanges of $\mathrm{N}$ between living organisms not masked by external inputs of N. Four whole plants (roots and shoots) of durum wheat and four of faba bean were collected from each plot during growth ( $1^{\text {st }}$ sampling period) and at maturity $\left(3^{\text {rd }}\right.$ sampling period), 10 plants of each species were taken during flowering ( $2^{\text {nd }}$ sampling period). A particular attention was necessary to recover the main part of the plant roots using garden forks, several diggings around the selected plants were sometimes necessary and the sampling was not possible on too dry soils. At the same times, two replicate soil samples were collected in $500 \mathrm{~mL}$ stainless steel cylinders from the $0-5 \mathrm{~cm}$ and $25-30 \mathrm{~cm}$ layers from each plot to determine the soil moisture and bulk density.

The soil near the roots was collected from the field, by careful separation by hand from roots, and preserved in iceboxes ( 4 plots $\times 3$ crop systems $\times 4$ replicates) then gently crushed by hand, without drying, through a $4 \times 4 \mathrm{~mm}$ grid sieve. The coarse and fine fractions were weighed, recognisable root fragments were separated and joined to their corresponding plant sample, and the fine fraction was kept without drying at $4{ }^{\circ} \mathrm{C}$ for analysis of microbial $\mathrm{N}$ on one part, analysis of total $\mathrm{N}$ after drying at $60^{\circ} \mathrm{C}$ and grinding at $0.2 \mu \mathrm{m}$ on the other part. The roots were separated from shoots and washed in deionized water. The root nodules were separated manually and the grains were separated from the shoots. All organs were dried at $60^{\circ} \mathrm{C}$ for 2 days and weighed. For subsequent $\mathrm{N}$ analysis, samples of each plant organ and soil were grouped and ground to $0.2 \mathrm{~mm}$ in a steel planetary ball mill.

The microbial $\mathrm{N}$ was determined within two days after sampling by fumigation-extraction (Brookes et al., 1985; Vance et al., 1987)

\footnotetext{
${ }^{1}$ There was a mistake in coordinates of Ibrahim et al. (2016) which are not in degrees minutes seconds as indicated but in degrees decimal minutes which corresponds to degrees minutes seconds of this paper.
} 
simultaneously with microbial C (Ibrahim et al., 2016). The fresh thin soil subsample equivalent to $10 \mathrm{~g}$ dry soil was fumigated with alcoholfree chloroform for $18 \mathrm{~h}$. The fumigated sample and a no fumigated control sample were shaken with $30 \mathrm{~mL}$ of a $0.5 \mathrm{~mol} \mathrm{~K}_{2} \mathrm{SO}_{4} \mathrm{~L}^{-1}$ aqueous solution for $45 \mathrm{~min}$, centrifuged for $10 \mathrm{~min}$ and sterilized by filtration using a $0.2 \mu \mathrm{m}$ membrane syringe. The filtrates were stored in sterile plastic tubes at $4{ }^{\circ} \mathrm{C}$ before $\mathrm{N}$ analysis which was performed in aqueous phase (Shimadzu TOC-VCSH analyzer). The soil microbial $\mathrm{N}$ concentrations (MB-cN) were calculated as the difference between the total $\mathrm{N}$ of the extracts of fumigated minus unfumigated divided by a factor $k_{\mathrm{N}}=0.54$ (Joergensen and Mueller, 1996). $\mathrm{N}$ in the unfumigated samples was assimilated to Inorganic-cN.

The root, shoot, nodule, grain organs of each plant as well as thin fraction of total soil were analysed in elemental analyzer (NA2000, Fisons Instruments) as in Ibrahim et al. (2016). All soil $\mathrm{N}$ concentrations (Total-cN in $\mathrm{mg} \mathrm{g}^{-1}, \mathrm{MB}-\mathrm{cN}$, and Inorganic-cN in $\mu \mathrm{g} \mathrm{mL}{ }^{-1}$ ) were converted to stocks $\left(\mathrm{g} \mathrm{N} \mathrm{m}^{-2}\right)$ in the $0-30 \mathrm{~cm}$ layer. The total organic $\mathrm{N}$ stock in $\mathrm{g} \mathrm{N} \mathrm{m}^{-2}$ in the $0-30 \mathrm{~cm}$ soil layer was:

Total oN stock $=300 \times b d \times$ Total-cN $(1-W p)(1-C f)$

where $b d$ was the bulk density of the plot, $W p$ was the gravimetric water content and $C f$ was the coarse gravel fraction. For a microbial extract of $30 \mathrm{~mL}$ from a subsample of mass $m_{S}$, the microbial N stock (MB-N) in $g$ $\mathrm{m}^{-2}$ was:

$\mathrm{MB}-\mathrm{N}=9 \times b d \times \mathrm{MB}-\mathrm{cN} \times(1-W p)(1-C f) / \mathrm{m}_{S}$

and the inorganic $\mathrm{N}$ stock was:

inorganicN $=9 \times b d \times$ Inorganic-cN $\times(1-W p)(1-C f) / \mathrm{m}_{S}$.

The $\mathrm{N}$ stock in each organ of the plants in $\mathrm{g} \mathrm{m}^{-2}$ was:

Plant organ $\mathrm{N}=\mathrm{m}_{P^{-}} \mathrm{cN} \times d \times m_{P} / n$

where $m_{P}$ is the total mass of the plant organ $(\mathrm{g}), n$ is the number of plants sampled, $\mathrm{m}_{P^{-}} \mathrm{cN}$ is the $\mathrm{N}$ concentration in the plant organ $\left(\mathrm{g} \mathrm{g}^{-1}\right)$ and $d$ is the plant density $\left(\mathrm{m}^{-2}\right)$.

After data collection, the statistical analyses enabled to test variance of sample replicates against variance of the plot replicates, to detect and check external values, to test variance of plot replicates against that of plot modalities and finally to obtain mean values (associated to confidence intervals of Figs. 3-5) for each sampling time and each modality. In a second time, we used these mean values to perform optimization of the parameters of the module of plant growth, in order to find a parameter set which simultaneously predict all these mean data.

\subsection{The $N$ transfer equations of the modelling tool $^{2}$}

As carbon and nitrogen are closely associated in living organisms, Pansu et al. (2014) proposed to model the MOMOS-N nitrogen cycle in the same way as the MOMOS-C carbon cycle (Pansu et al., 2010). MOMOS (Fig. 1) was defined as a five compartment model (MB, VL, VS, HL and HS) centred on soil microbial biomass (MB) in a matrix equation given by Pansu et al. (2010) for C cycle, by Pansu et al. (2014) for N cycle and submitted to a mathematical analysis by Hammoudi et al. (2014). Each model parameter was linked to temperature $f(T)$ and moisture $f(\theta)$ functions previously defined and used in Pansu et al. (2010, 2014) and Ibrahim et al. (2016). In this study, the soil water content $\theta$ was predicted using the soil water model SAHEL (Penning de Vries et al., 1989).

In the equation system, the MOMOS-N model matrix $\mathbf{A}_{\mathbf{N}}$ defining $\mathrm{N}$ flows was found similar to the MOMOS-C model matrix $\mathbf{A}_{\mathbf{C}}$ defining $\mathrm{C}$

\footnotetext{
${ }^{2}$ Sections 2.2 and 2.3 show the N-cycle-specific equations complementary to the previous modelling equations (Pansu et al., 2014; Ibrahim et al., 2016). Readers who are not familiar with the equations can focus only on the results (section 3) and the discussions (section 4).
}

flows, only the central term was changed: The central term of $\mathbf{A}_{\mathbf{C}}$ defines microbial respiration when the central term of $\mathbf{A}_{\mathbf{N}}$ defines the microbial exchanges with inorganic $\mathrm{N}$ (InorgN, Fig. 1) by a function $f\left(x_{C, M B}, x_{N, M B}\right)$ of $\mathrm{C}$ and $\mathrm{N}$ contents of microbial biomass (MB, Fig. 1). Additionally to links between parameters and weather data, the respiration rate $\left(k_{\text {resp }}\right)$ was found as linked to the soil fine fraction $0-20 \mu \mathrm{m}$; the rates of enzymatic digestion of labile $\left(k_{\mathrm{VL}}\right)$ and stable $\left(k_{\mathrm{VS}}\right)$ plant materials as well as the microbial mortality rate $\left(k_{\mathrm{MB}}\right)$ were found linked to the $\mathrm{C} / \mathrm{N}$ ratio of each organic input (Pansu et al., 2010, 2014). The values in optimum pedoclimatic conditions for the parameters $k_{\mathrm{HL}}$, $k_{\mathrm{HS}}, k_{\mathrm{HLS}}$ remained unchanged from the previous experiments of Pansu et al. (2010, 2014). The present study used again the $\mathbf{A}_{\mathbf{N}}$ matrix and parameters defined for the $\mathrm{N}$ cycle (Pansu et al., 2014). Only the initial values of the vector $\mathbf{x}_{\mathbf{N}}$ of the $\mathrm{N}$ contents of each compartment (known at the model setup with ${ }^{15} \mathrm{~N}$ tracers), and the continuous inputs of $\mathrm{N}$ from the different necromasses (NC) of $k$ organs of $j$ plants in the vector $\mathbf{B}_{\mathrm{N}}^{j, k}$ were estimated by the general equation:

$\dot{\mathbf{x}}_{\mathrm{N}}=f(T) f(\theta) \mathbf{A}_{\mathrm{N}} \mathbf{x}_{\mathrm{N}}+\sum_{j} \sum_{k} \mathbf{B}_{\mathrm{N}}^{j, k}$

where $\mathbf{A}_{\mathrm{N}}$ is the MOMOS-N model matrix (Pansu et al., 2014)

$\mathbf{A}_{\mathrm{N}}=\left|\begin{array}{ccccc}-k_{\mathrm{VL}} & 0 & 0 & 0 & 0 \\ 0 & -k_{\mathrm{VS}} & 0 & 0 & 0 \\ k_{\mathrm{VL}} & k_{\mathrm{VS}} & -\left(f\left(x_{\mathrm{C}, \mathrm{MB}} x_{\mathrm{N}, \mathrm{MB}}\right)\right. & k_{\mathrm{HL}} & k_{\mathrm{HS}} \\ & & \left./ f(T) f(\theta) x_{\mathrm{N}, \mathrm{MB}}+k_{\mathrm{MB}}\right) & & \\ 0 & 0 & k_{\mathrm{MB}} & -\left(k_{\mathrm{HL}}+k_{\mathrm{HLS}}\right) & 0 \\ 0 & 0 & 0 & k_{\mathrm{HLS}} & -k_{\mathrm{HS}}\end{array}\right|$

and $\mathbf{x}_{\mathrm{N}}=$ is the vector content of each compartment, respectively, $\dot{\mathbf{x}}_{\mathrm{N}}$ is the daily output flow of each compartment, and $\mathbf{B}_{\mathrm{N}}^{j, k}$ is the vector of external inputs of $\mathrm{N}$. In this unfertilized intercropping sustained only by restitution of dead materials (organic fertilizer $\mathrm{OF} N$ and added inorganic $\mathrm{N}$ aiN of Fig. $1=0$ for all $t$ ), $j$ defines the plant (cereal or legume) and $k$ defines the plant organ or symbiont (litter-NC, root-NC, or nodule-NC). Using $f_{\mathrm{S} j, k}$ the stable fraction of each plant organ $j, k$ (data invariant with time which can be estimated by the TAO model from fiber measurements (Thuriès et al., 2002), near infrared (Kaboré et al., 2012), or solid state nuclear magnetic resonance spectrometry (Pansu et al., 2017) and stored in a data base. The $\mathbf{B}_{\mathrm{N}}$ vector of $\mathrm{N}$ inputs was adjusted daily to $C$ inputs (Ibrahim et al., 2016) by the balance equation:

$\mathrm{B}_{\mathrm{N}, \mathrm{VL}}^{j, k}(t)=\left(\frac{1}{\eta_{\mathrm{NCj}, k}}-\frac{f_{s j, k}}{\eta_{\mathrm{VS} j, k}}\right) \mathrm{C}_{j, k}, \quad \mathrm{~B}_{\mathrm{N}, \mathrm{VS}}^{j, k}(t)=\frac{f_{s j, k}}{\eta_{\mathrm{VS} j, k}} \mathrm{C}_{j, k}$,

$\mathrm{B}_{\mathrm{N}, \mathrm{MB}}^{j, k}(t)=\mathrm{B}_{\mathrm{N}, \mathrm{HL}}^{j, k}(t)=\mathrm{B}_{\mathrm{N}, \mathrm{HS}}^{j, k}(t)=0$

where $C_{j, k}$ is the daily input of $C$ from organ $k$ of plant $j$ (Ibrahim et al., 2016), $\eta_{\mathrm{NC} j, k}$ is the C:N ratio of a given necromass $\mathrm{NC}_{j, k}$ (assuming data invariant with time which can be estimated by C,N analysis of each plant organ and stored in a data base), and $\eta_{\mathrm{VSj}, k}$ is the C:N ratio of its stable fraction assuming $\eta_{\mathrm{VSj}, k}=50 \eta_{\mathrm{NCj}, k}$ from NC ${ }^{14} \mathrm{C}:{ }^{15} \mathrm{~N}$ ratios in the range 200-500 at the end of field incubation of Pansu et al. (2010, 2014). For each incubation time, the flow of the total organic $\mathrm{N}$ is the negative of the derivative of the mineralized or immobilized $\mathrm{N}$ and is expressed by the sum of the flows $\dot{x}_{i, N}$ of $\mathrm{N}$ from each $i$ compartment:

$\dot{N}=\sum_{i=1}^{5} \dot{x}_{i, N}=-f\left(x_{\mathrm{C}, \mathrm{MB}}, x_{\mathrm{N}, \mathrm{MB}}\right)$

where positive values of the function $f\left(x_{\mathrm{C}, \mathrm{MB}}, x_{\mathrm{N}, \mathrm{MB}}\right)$ correspond to the net mineralization of microbial $\mathrm{N}$ and negative values correspond to the net microbial immobilization of inorganic $\mathrm{N}$. The function $f\left(x_{\mathrm{C}, \mathrm{MB}}, x_{\mathrm{N}, \mathrm{MB}}\right)$ of equation (7) was defined using $\eta_{M B}^{\text {lim }}$, the target value for the $\mathrm{C}: \mathrm{N}$ ratio of the $\mathrm{MB}\left(\eta_{\mathrm{MB}}\right)$, assuming a constant $\eta_{M B}^{\lim }$ ratio throughout incubation (homeostasis): 


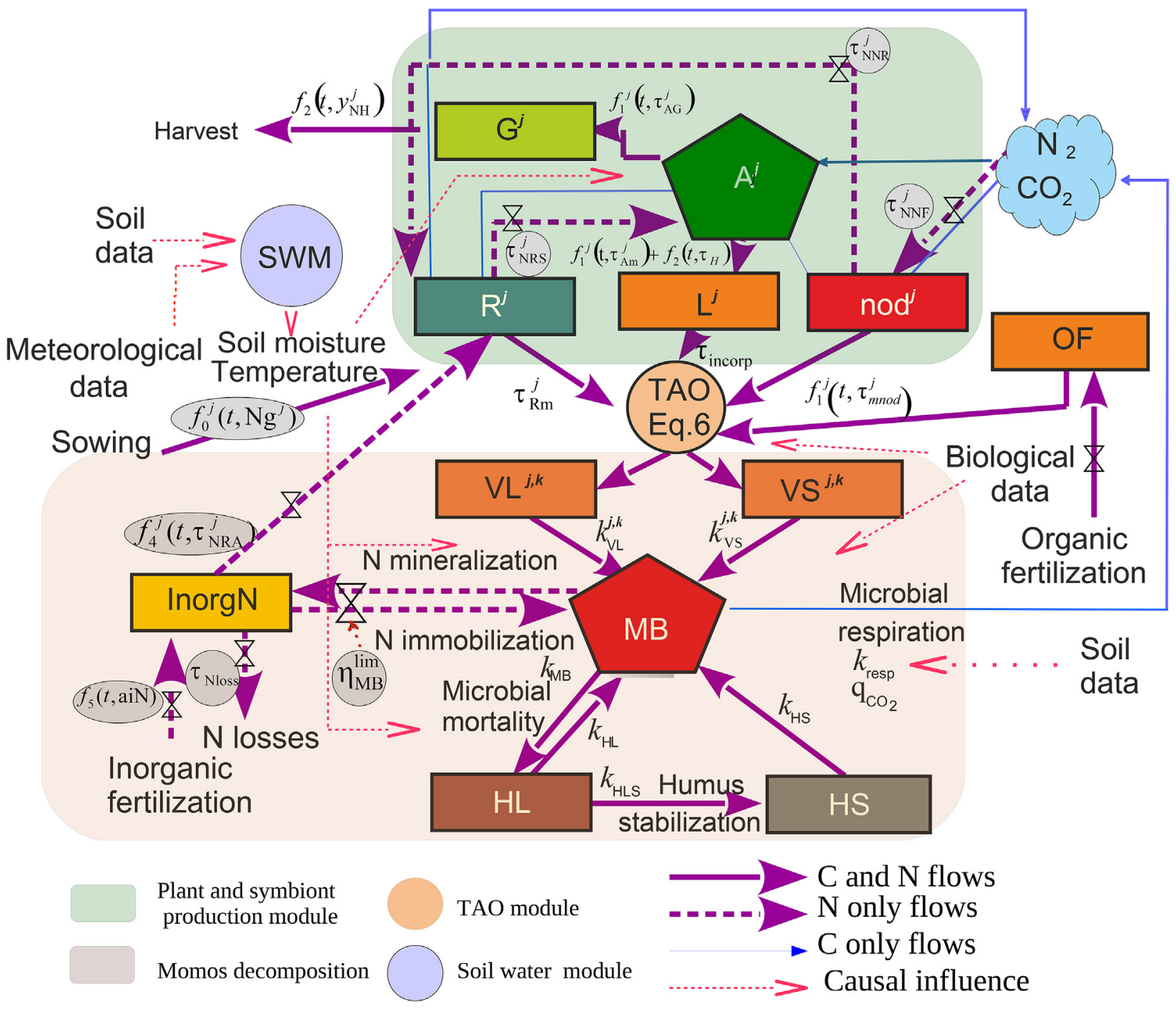

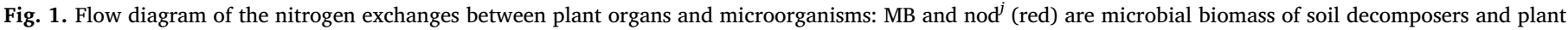

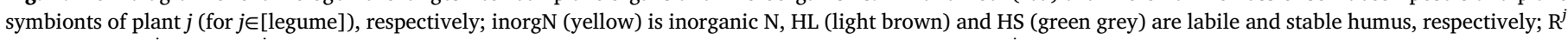

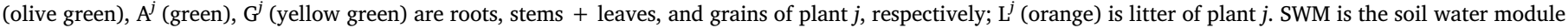

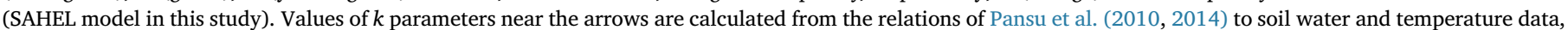

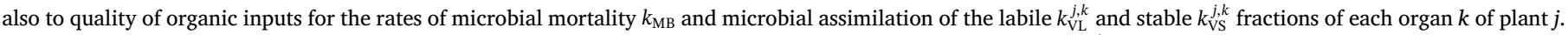

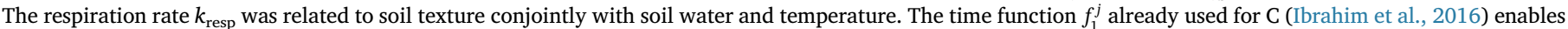

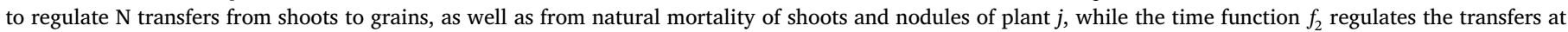

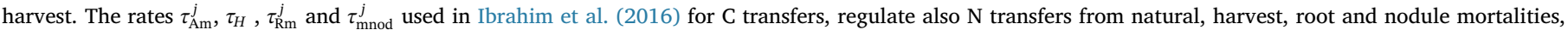

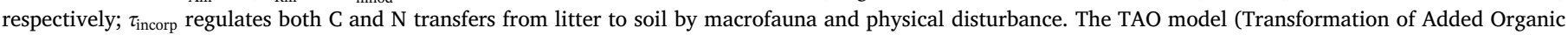

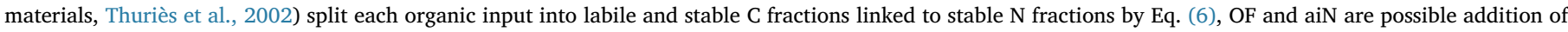

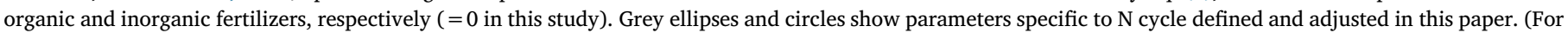
interpretation of the references to colour in this figure legend, the reader is referred to the Web version of this article.)

$f\left(x_{\mathrm{C}, \mathrm{MB}}, x_{\mathrm{N}, \mathrm{MB}}\right)=x_{N, M B}-\frac{x_{C, M B}}{\eta_{M B}^{\lim }}$

$\eta_{M B}^{\lim }$ was the only decomposition parameter adjusted for each plot, all the other parameters and functions linking them to environmental conditions being those of ${ }^{14} \mathrm{C}$ simulations (Pansu et al., 2010) and used in the agro-ecological simulations of this paper. The $\mathrm{N}$ initial values of $\mathrm{BM}, \mathrm{HL}$, and HS compartments where those found for C (Ibrahim et al., 2016) divided by respective C:N ratios, assuming initial MB C:N ratio $=\eta_{M B}^{\lim }$ and initial HL C:N ratio $=3 \eta_{M B}^{\lim }$. Only initial HS C:N ratio was optimized ( $\eta_{\text {HS }}$ Table 3 ).

The $\mathrm{C}$ flows were previously modelled from the atmosphere to leaves and then to roots and microorganisms, whereas the $\mathrm{N}$ flow must be modelled from the soil or atmosphere to roots and symbiotic nodules, and then to the aerial parts (Fig. 1), which induces the equations in 2.3 below.

\subsection{Modelling $N$ transfers in plants and microbial symbiosis}

Plain bold purple arrows of the flow diagram of Fig. 1 show the $\mathrm{N}$ transfers closely associated with most of the $\mathrm{C}$ transfers during plant production and microbial decomposition except few specific transfers for $\mathrm{C}$ (thin blue arrows) or $\mathrm{N}$ (dashed bold purple arrows). Using the previous parameters and relationships of Pansu et al. (2010) and Ibrahim et al. (2016), the only parameters added specifically to model the $\mathrm{N}$ cycle were those in Fig. 1 (grey ellipses) and Table 3. The nitrogen contents in the roots $y_{\mathrm{NR}}^{j}$ of a given plant $j$ was driven by:

$\frac{d y_{\mathrm{N}}^{j, R}}{d t}=f_{0}^{j}(t, \mathrm{Ng})+f_{4}^{j}\left(t, \tau_{\mathrm{NRA}}^{j}\right) y^{j, R}+\tau_{\mathrm{NNR}}^{j} y_{\mathrm{N}}^{j, n o d}-y_{\mathrm{N}}^{j, R}\left(\tau_{\mathrm{NRS}}^{j}+\tau_{\mathrm{Rm}}^{j}\right)$

where $f_{0}^{j}\left(t, \mathrm{Ng}^{j}\right)=\mathrm{Ng}^{j}$, the $\mathrm{N}$ stock of seed grain, when $t=t_{\text {sowing }}$ 
Table 1

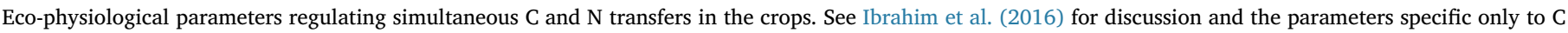
transfers.

\begin{tabular}{|c|c|c|c|c|c|c|}
\hline \multirow[t]{2}{*}{ Function } & \multirow[t]{2}{*}{ Symbol } & \multirow[t]{2}{*}{ Description } & \multicolumn{4}{|c|}{ Cropping system } \\
\hline & & & Units & Wheat $^{\mathrm{a}}$ & Faba beans ${ }^{\mathrm{a}}$ & Interc $^{\mathrm{b}}$ \\
\hline Mortality & $\tau_{R m}^{j}$ & Root mortality rate & $\mathrm{d}^{-1}$ & 0.001 & & 0.051 \\
\hline$j \in[$ Durum wheat $]$ & $\tau_{A m}^{j}$ & Aerial mortality rate & $\mathrm{d}^{-1}$ & 0.537 & & $10^{-5}$ \\
\hline \multirow{3}{*}{$\begin{array}{l}\text { Mortality } \\
j \in[\text { Faba bean }]\end{array}$} & $\tau_{R m}^{j}$ & Root mortality rate & $d^{-1}$ & & 0.365 & 0.515 \\
\hline & $\tau_{A m}^{j}$ & Aerial mortality rate & $\mathrm{d}^{-1}$ & & 0.00064 & 0.052 \\
\hline & $\tau_{\text {mnod }}^{j}$ & Nodule mortality rate & $\mathrm{d}^{-1}$ & & $10^{-6}$ & $10^{-6}$ \\
\hline Litter incorporation & $\tau_{\text {incorp }}$ & Litter to soil incorporation rate & $\mathrm{d}^{-1}$ & 0.0014 & 0.0868 & 0.0333 \\
\hline
\end{tabular}

a Plant $j$ in pure cropping.

b Plant $j$ in intercropping.

and $=0$ when $t \neq t_{\text {sowing }}, f_{4}^{j}\left(t, \tau_{\mathrm{NRA}}^{j}\right)$ regulates inorganic $\mathrm{N}$ absorption by roots of each plant at the rate $\tau_{\mathrm{NRA}}^{j}$ of the root biomass $y^{j, R}$ expressed in C stock units (Ibrahim et al., 2016), $\tau_{\mathrm{NNR}}^{j} y_{\mathrm{N}}^{j, n o d}$ regulates the $\mathrm{N}$ transfer from symbiotic nodules to root xylem $\left(y_{\mathrm{N}}^{j, \text { nod }}\right.$ is the nodule $\mathrm{N}$ stock $=0$ for $j \notin\left[\right.$ legume]) at rate $\tau_{\mathrm{NNR}}^{j}$, and the other terms regulate the losses of root $\mathrm{N}$ by transfer to shoots at rate $\tau_{\mathrm{NRS}}^{j}$ and root mortality at the rate $\tau_{\mathrm{Rm}}^{j}$ defined by Ibrahim et al. (2016), see Table 1 .

The daily change in the inorganic $\mathrm{N}$ compartment was the sum of MB mineralization or immobilization (Eq. (7)) and possible inorganic fertilization minus root absorptions and losses from the intercropping system:

$\frac{d_{\text {inorgN }}}{d t}=f\left(x_{\mathrm{C}, \mathrm{MB}}, x_{\mathrm{N}, \mathrm{MB}}\right)+f_{5}(t$, aiN $)-\sum_{j} f_{4}^{j}\left(t, \tau_{\mathrm{NRA}}^{j}\right) \mathrm{y}^{j, R}-\tau_{\mathrm{Nloss}}$ inorgN

using $f\left(x_{\mathrm{C}, \mathrm{MB}}, x_{\mathrm{N}, \mathrm{MB}}\right)$ defined in Eq. ( 8$), f_{4}^{j}\left(t, \tau_{\mathrm{NRA}}^{j}\right) \mathrm{y}^{j, R}$ defined in eq. (9), $\tau_{\text {Nloss }}$ inorgN being the global loss flow of inorganic $\mathrm{N}$ in environment, and aiN being the rate of possible addition of inorganic $\mathrm{N}$ fertilizer, $f_{5}(t$, aiN $)=0$ for all times in this experiment (no fertilization). The $\mathrm{N}$ stock in the legume symbiotic nodules was driven by:

$\frac{d y_{\mathrm{N}}^{j, n o d}}{d t}=\tau_{\mathrm{NNF}}^{j} y^{j, n o d}-\left(\tau_{\mathrm{NNR}}^{j}+\tau_{\mathrm{mnod}}^{j}\right) y_{\mathrm{N}}^{j, n o d}$

where $\tau_{\mathrm{NNF}}^{j}$ is the rate of symbiotic fixation by unit of nodule C stock $y^{j, \text { nod }}$ (Ibrahim et al., 2016), $\tau_{\mathrm{mnod}}^{j}$ is the nodular mortality and $\tau_{\mathrm{NNR}}^{j}$ the transfer rate to roots (see eq. (9)); all $\tau$ values $=0$ for $j \notin$ [legume].

The $\mathrm{N}$ contents $y_{\mathrm{NA}}^{j}$ of aerial shoots of each plant $j$ were driven by:

$\frac{d y_{\mathrm{N}}^{j, A}}{d t}=y_{\mathrm{N}}^{j, R} \tau_{\mathrm{NRS}}^{j}-y_{\mathrm{N}}^{j, A}\left(f_{1}^{j}\left(\left(\mathrm{t}, \tau_{\mathrm{Am}}^{j}\right)+\left(t, \tau_{\mathrm{AG}}^{j}\right)\right)+f_{2}\left(t, \tau_{H}\right)\right)$

where the first term on the right-hand-side expresses the $\mathrm{N}$ inputs from roots, and the second term expresses the $\mathrm{N}$ outputs to litter (by natural mortality and harvest) and to grains, assuming that, for a given plant, the same time function $f_{1}^{j}$ drives the $\mathrm{C}$ and $\mathrm{N}$ transfers to grains and to litter; $f_{2}=0$ for all time except at the harvest where $f_{2}=1$ (Ibrahim et al., 2016).

The grain growth takes $\mathrm{N}$ from the shoots:

$\frac{d y_{\mathrm{N}}^{j, G}}{d t}=y_{\mathrm{N}}^{j, A} f_{1}^{j}\left(t, \tau_{\mathrm{AG}}^{j}\right)-f_{2}\left(t, y_{\mathrm{N}}^{j, H}\right)$

where $y_{\mathrm{N}}^{j, H}$ is the $\mathrm{N}$ exported in grains of each plant $j$ at harvest time $t_{\mathrm{H}}$, and is 0 for all $t \neq t_{\mathrm{H}}$.

The litter $y_{\mathrm{N}}^{j, L}$ of each plant $j$ was modelled as the balance of accumulation of aerial parts by mortality and by cutting at harvest, minus the litter transferred by macrofauna to the $0-30 \mathrm{~cm}$ soil layer: $\frac{d y_{\mathrm{N}}^{j, L}}{d t}=y_{\mathrm{N}}^{j, A}\left(f_{1}^{j}\left(\mathrm{t}, \tau_{\mathrm{Am}}^{j}\right)+f_{2}\left(t, \tau_{H}\right)\right)-y_{\mathrm{N}}^{j, L} \tau_{\text {incorp }}$

assuming that $\tau_{\text {incorp}}$, the rate of litter incorporation in the soil by macrofauna, is the same for all plant (no selection). There was no fertilization in this trial and so OF $\mathrm{N}=$ aiN $=0$ for all $t$.

\subsection{Statistical tools}

The accuracy of model predictions was tested in three ways:

- 1) for all state variables simultaneously, we compared predictions by the model $y$ of the mean measured values $x$ during the experiment using:

$y=(\mathrm{a} \pm \Delta \mathrm{a}) x+(\mathrm{b} \pm \Delta \mathrm{b})$

where $\Delta \mathrm{a}$ and $\Delta \mathrm{b}$ were the confidence intervals associated to slope and zero coordinate, respectively; no absolute bias when $\mathrm{b} \pm \Delta \mathrm{b}$ not significantly different of zero, no relative bias when a $\pm \Delta$ a not significantly different of 1 ,

- 2) for each data series, we compared model prediction to the variance around mean value using a Fisher test:

$F=\frac{\sum_{i=1}^{n}\left(y_{i}-\bar{y}_{i}\right)^{2}}{\sum_{i=1}^{n}\left(y_{i}-\hat{y}_{i}\right)^{2}}$

where $i$ was the measurement number, $n$ the total available data for each series ( 3 for the three measurements, 4 if we consider the value 0 at time 0 , for plant organs), $y_{\mathrm{i}}$ was each of the measured values at time $i \overline{y_{i}}$ was their mean value and $\hat{y}_{i}$ was their model prediction at time $i$. $\mathrm{F}>1$ indicates that the data are better predicted by the model than by a random distribution around their mean value. Significance levels are $F_{3 / 4}$ or $F_{2 / 3}$ of tables $F$, the model predictions being entirely determined by the parameter values of Pansu et al. (2010, 2014), Ibrahim et al. (2016) and Table 3 of this paper,

- 3) for each data, was the prediction included or not in the confidence interval associated with its measurement?

Statistical tests were performed using Statgraphics (www. sigmaplus.fr). VENSIM (http://www.vensim.com/) was used for moisture calculations using the SAHEL model (Penning de Vries et al., 1989) and for all C and N cycle calculations coupling TAO, MOMOS and the $\mathrm{C}$ production and $\mathrm{N}$ transfer modules for the cereal/legume intercropping. Euler's method was used for numerical integration of the differential system and parameters were fitted using Powell's conjugate 


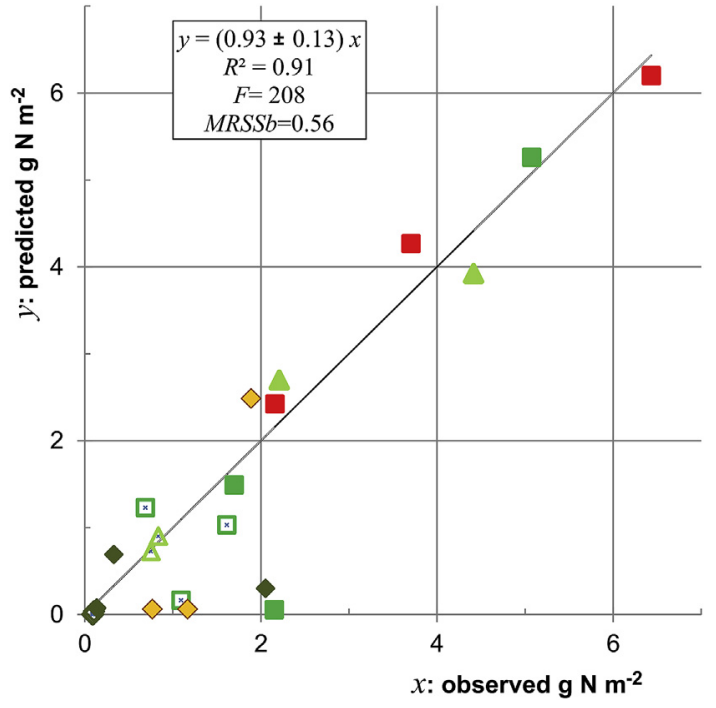

Fig. 2. Simultaneous model predictions of $\mathrm{N}$ stocks in the means of the measured state variables at different vegetation stages of the intercropping experiment: red squares are $\mathrm{N}$ of microbial biomass, yellow diamonds are soil inorganic $\mathrm{N}$, plain green square are $\mathrm{N}$ shoots of faba bean, open green squares are $\mathrm{N}$ shoots of durum wheat, plain yellow green triangles are $\mathrm{N}$ grains of faba bean, open yellow green triangles are $\mathrm{N}$ grains of durum wheat, plain olive green diamonds are $\mathrm{N}$ roots of faba bean, open olive green diamonds are $\mathrm{N}$ roots of durum wheat, RSSb is residual sum of square to bisector. (For interpretation of the references to colour in this figure legend, the reader is referred to the Web version of this article.)

gradient descent method.

\section{Results}

\subsection{Modelling measured state variables from $N$ flows}

\subsubsection{All state variables simultaneously}

The plant module enables to predict accurately all the state variables measured at different growth stages in the intercropping system. The fitting by equation (15) (Fig. 2) showed an adjustment significant at $p<10^{-4}$ of predicted $v s$ measured values and explained $91 \%$ of the variance $\left(R^{2}\right.$ value on Fig. 2). The values were inside the mean residual sum of square of their distance to the bisector (RSSb on Fig. 2), except:

(1) the two last IN points (yellow diamonds in Fig. 2) were slightly underestimated near zero by the model, which was plausible considering the high demand of inorganic $\mathrm{N}$ by living organisms;

(2) roots (green olive diamond in Fig. 2)) and shoots (green squares in Fig. 2)) of faba bean at 191 day after the seedling; this point was particular in faba bean physiology (Fig. 5); it was the time of grain growth, which took $\mathrm{N}$ from shoots and the simultaneous time of depletion of symbiotic nodules which transferred $\mathrm{N}$ to roots; the measured root $\mathrm{N}$ was exceptionally high at $191 \mathrm{~d}$ near the level of the measured shoot $\mathrm{N}$; the modelled increase of root $\mathrm{N}$ occurred too late to better fit the measured value, when the modelled decrease of shoot $\mathrm{N}$ (transfer to grain $\mathrm{N}$ ) occurred about 10 days too early to fit the measured values.

Excepting these 4 slight under predictions, the 18 other measured values of state variables were accurately predicted by the above equation system, adjusted to the parameters of Tables 1 and 3 (see section 3.2 below).

\subsubsection{Predicting microbial control of organic $N$}

The $\mathrm{N}$ stocks and exchanges between organic compartments are
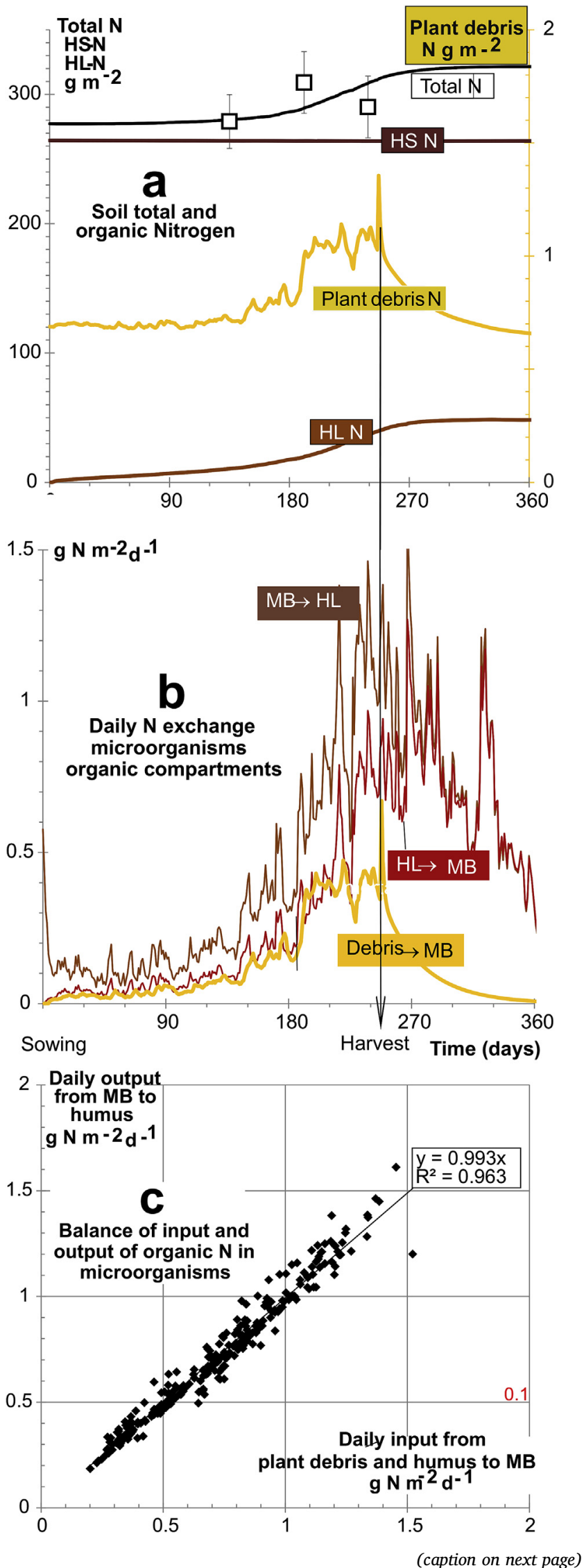
Fig. 3. N organic forms regulated by microorganisms: a) predicted and measured values with $95 \%$ confidence intervals of stocks of soil total N, N predicted in plant debris (orange), N predicted in labile humus (HL, light brown) and in stable humus (HS, green grey), b) continuous $\mathrm{N}$ exchange between microorganisms, plant debris and labile humus, c) continuous balance of organic $\mathrm{N}$ inputs and outputs of the microbial compartment. (For interpretation of the references to colour in this figure legend, the reader is referred to the Web version of this article.)

summarized in Fig. 3. The predicted increase of $44 \mathrm{~g} \mathrm{~m}^{-2}$ in total $\mathrm{N}$ was not significantly outside the confidence interval of the measured data. It was mainly due to the increase in the labile humus of microbial origin (HL N, Fig. 3a), the model predicted a nearly constant stable compartment (HS N). The amount of total plant debris remaining in the top soil from five sources (roots and litter of durum wheat and faba bean, and symbiotic nodules) was predicted as approximately constant about $0.6-0.7 \mathrm{~g} \mathrm{~N} \mathrm{~m}^{-2}$ during the entire cycle except for an increase which began around 150 days after sowing, flattening out to $0.9-1.1 \mathrm{~g} \mathrm{~N} \mathrm{~m}^{-2}$ 200-250 days after sowing, and peaking at $1.4 \mathrm{~g} \mathrm{~N} \mathrm{~m}^{-2}$ at harvest (orange curve in Fig. 3a).

This plant debris $\mathrm{N}$ stock was modelled in Fig. $3 \mathrm{~b}$ as the incorporation of the daily input from plant organ mortality (See Table 1 remembering the mortality rates of Ibrahim et al., 2016 retained also for $\mathrm{N}$ transfers) minus the daily microbial assimilation of debris, which was about $0.1 \mathrm{~g} \mathrm{~N} \mathrm{~m}^{-2} \mathrm{~d}^{-1}$ from sowing to $150 \mathrm{~d}$ after sowing. After $150 \mathrm{~d}$, the microbial assimilation increased to $0.3-0.5 \mathrm{~g} \mathrm{~N} \mathrm{~m}^{-2} \mathrm{~d}^{-1}$, reached a peak of $0.7 \mathrm{~g} \mathrm{~N} \mathrm{~m}^{-2} \mathrm{~d}^{-1}$ immediately after harvest and then decreased quasi exponentially to below $0.01 \mathrm{~g} \mathrm{~N} \mathrm{~m}^{-2} \mathrm{~d}^{-1}$ one year after sowing (Fig. $3 \mathrm{~b}$ ). The $\mathrm{N}$ microbial assimilation rate from plant debris was predicted as being close to the $\mathrm{N}$ microbial assimilation rate from labile humus during the 1 st step of plant growth, from sowing to $210 \mathrm{~d}$ after sowing. The $\mathrm{N}$ assimilation rate from labile humus then became increasingly greater than the $\mathrm{N}$ assimilation of plant debris until 2 months after harvest. Labile humus was predicted as almost the only source of $\mathrm{N}$ for microorganisms 2 months after the harvest (Fig. 3b).

During the entire intercropping cycle, the daily output of $\mathrm{N}$ from microorganisms to humus by microbial mortality (Fig. 3b) was predicted as approximately the sum of daily inputs by enzymatic assimilation of plant debris and humus, with variations linked to climate conditions. Microbial inputs ( $x$ in Fig. 3c) were significantly correlated with microbial outputs ( $y$ in Fig. 3c) using the equation $y=0.993 x$, indicating that daily organic $\mathrm{N}$ remaining in microorganisms was only $0.7 \%$ of the organic $\mathrm{N}$ exchanged by these microorganisms. The model need not an additional arrow and corresponding equation to take microbial assimilation of organic $\mathrm{N}$ into account, it simply results from the difference between microbial assimilation of organic materials and the $\mathrm{N}$ output by microbial mortality. The other part of $\mathrm{N}$ required for microbial functioning was immobilized from inorganic soil $\mathrm{N}$ (see 3.1.3 below).

\subsubsection{Predicting microbial control of inorganic $N$}

Fig. 4 summarizes the stocks and inorganic $\mathrm{N}$ exchanges for microbial decomposers and symbiotic microorganisms. These stocks and exchanges were small compared to the stocks and exchanges of organic forms of $\mathrm{N}$ (Fig. 3): microbial $\mathrm{N}$ (Fig. 4a) amounted to $0.3-2.8 \%$ of the total organic $\mathrm{N}$ and $3-23 \%$ of $\mathrm{N}$ of the labile humus (HL compartment, Fig. 3a), inorganic $\mathrm{N}$ (Fig. 4a) ranged from $0.03-3.4 \%$ of the total organic $\mathrm{N}$ and $0.3-30 \%$ of HL N (Fig. 3a). Fig. 4a shows an increase in microbial $\mathrm{N}$ which follows the increase in plant restitution during intercropping from $1-2 \mathrm{~g} \mathrm{~N} \mathrm{~m}^{--2}$ at sowing to $6-7 \mathrm{~g} \mathrm{~N} \mathrm{~m}^{--2}$ at harvest, and a decrease after harvest when the $\mathrm{C}$ supply from plant photosynthesis ceased. The corresponding increase observed and predicted for microbial C by Ibrahim et al. (2016) varied from $10-20 \mathrm{~g} \mathrm{C} \mathrm{m}^{--2}$ at sowing to $60-70 \mathrm{~g} \mathrm{C} \mathrm{m}^{--2}$ at harvest. As for MB-C, the MB-N data were significantly predicted at $\mathrm{p}<0.02$ (Table 2) by MOMOS with all
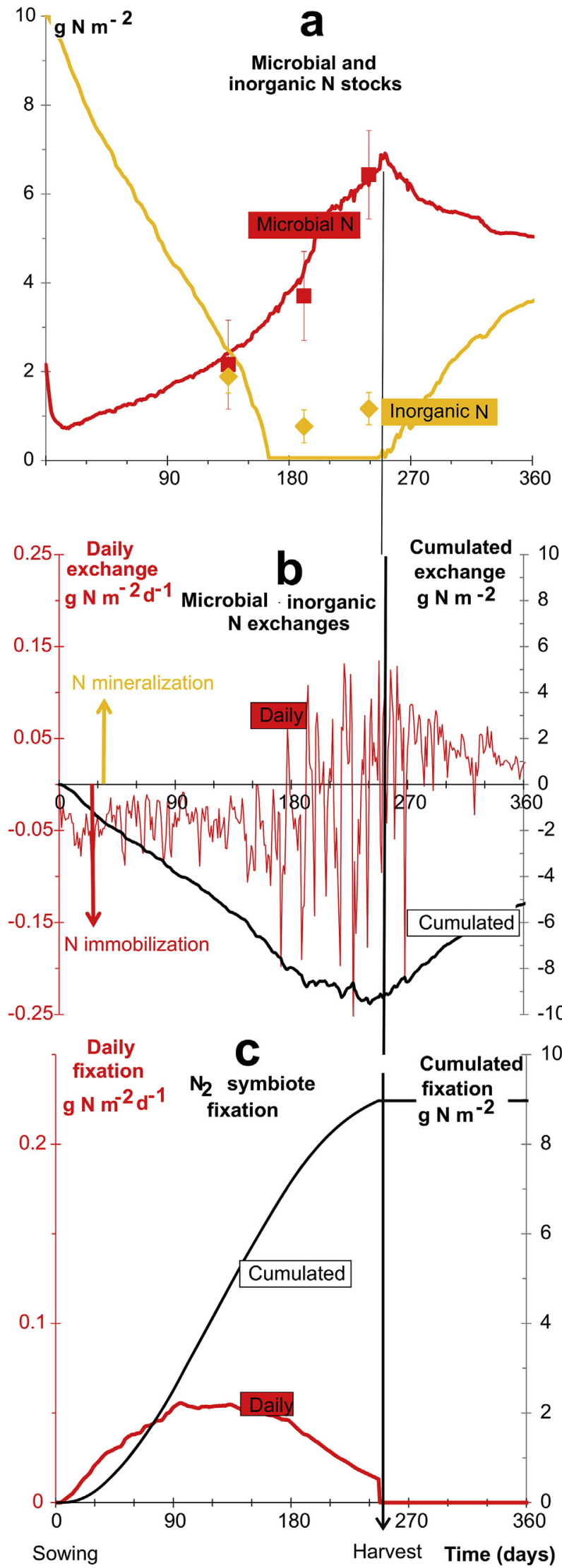

(caption on next page) 
Fig. 4. Microbial exchanges with inorganic nitrogen: a) predicted and measured values, with 95\% confidence intervals of inorganic (yellow) and microbial (red) $\mathrm{N}$ stocks in the intercropping system, b) prediction of continuous (red) and cumulated (black) microbial exchanges of inorganic $\mathrm{N}$ in the intercropping system, c) prediction of continuous (red) and cumulated (black) fixation of atmospheric $\mathrm{N}_{2}$ in the intercropping system. (For interpretation of the references to colour in this figure legend, the reader is referred to the Web version of this article.)

\section{Table 2}

Significance of model prediction for each data series (Eq. (16)); see Fig. 1 for variable symbols: $\mathrm{MB}-\mathrm{N}$ is $\mathrm{N}$ of soil microbial biomass, inorgN is soil inorganic $\mathrm{N}, \mathrm{A}^{\mathrm{FB}}-\mathrm{N}$ is faba bean shoot $\mathrm{N}, \mathrm{R}^{\mathrm{FB}}-\mathrm{N}$ is faba bean $\operatorname{root} \mathrm{N}$, $\mathrm{G}^{\mathrm{FB}}-\mathrm{N}$ is faba bean grain $\mathrm{N}, \mathrm{A}^{\mathrm{DW}}-\mathrm{N}$ is durum wheat shoot $\mathrm{N}, \mathrm{R}^{\mathrm{DW}}-\mathrm{N}$ is durum wheat root $\mathrm{N}, \mathrm{G}^{\mathrm{DW}}-\mathrm{N}$ is durum wheat grain $\mathrm{N}$, NS is not significant, ${ }^{* *}$ and ${ }^{* * *}$ are significant at $p<0.02$ and $p<0.01$, respectively.

\begin{tabular}{lll}
\hline Variable & $F$ & \\
\hline $\mathrm{MB}-\mathrm{N}$ & 21.4 & $* *$ \\
inorgN & 0.4 & $\mathrm{NS}$ \\
$\mathrm{A}^{\mathrm{FB}}-\mathrm{N}$ & 3.0 & $\mathrm{NS}$ \\
$\mathrm{R}^{\mathrm{FB}}-\mathrm{N}$ & 0.9 & $\mathrm{NS}$ \\
$\mathrm{G}^{\mathrm{FB}}-\mathrm{N}$ & 27.8 & $* *$ \\
$\mathrm{~A}^{\mathrm{DW}}-\mathrm{N}$ & 0.9 & $\mathrm{NS}$ \\
$\mathrm{R}^{\mathrm{DW}}-\mathrm{N}$ & 0.4 & $\mathrm{NS}$ \\
$\mathrm{G}^{\mathrm{DW}}-\mathrm{N}$ & 113.9 & $* * *$ \\
\hline
\end{tabular}

predictions within the confidence intervals of the observed values.

The flow of inorganic N (Fig. 4b) was predicted as being net immobilization by microorganisms during the early stages of intercropping until $150 \mathrm{~d}$ after sowing when the first periods of net mineralization occurred, followed by swings between mineralization and immobilization, depending on weather conditions, and then by net mineralization after harvest. The cumulated immobilization was predicted as maximal at near $9 \mathrm{~g} \mathrm{~N} \mathrm{~m}^{-2}$ in the period $150-270 \mathrm{~d}$ after sowing, then reducing by mineralization giving a balance of $5 \mathrm{~g}$ immobilized $\mathrm{N} \mathrm{m}^{-2}$ at $360 \mathrm{~d}$ (Fig. 4b). The stock of inorganic $\mathrm{N}$ (Fig. 4a) was modelled as decreasing significantly under the effect of the microbial and plant uptake from $10 \mathrm{~g} \mathrm{~N} \mathrm{~m}^{-2}$ at sowing to $0.06 \mathrm{~g} \mathrm{~N} \mathrm{~m}^{-2}$ $166 \mathrm{~d}$ after sowing. It remained low until harvest when it increased again following the decrease in microbial biomass. The predicted values were within the confidence interval of the first measurement and were only slightly under-predicted for the other measurements (Fig. 4a).

The continuous fixation of atmospheric N (Fig. 4c) was predicted as having a quasi linear increase (conjointly with a decrease of inorganic $\mathrm{N}$ stock (Fig. 4a) from 10 to $90 \mathrm{~d}$ after sowing reaching a peak of $0.05 \mathrm{~g} \mathrm{~N} \mathrm{~m}^{-2} \mathrm{~d}^{-1}$ between 90 and $180 \mathrm{~d}$ and then decreasing quasi linearly until about $0.01 \mathrm{~g} \mathrm{~N} \mathrm{~m}^{-2} \mathrm{~d}^{-1}$ at harvest when it ceased. Overall, the total $\mathrm{N}$ fixation by symbiotic nodular rhizobia was estimated at $9 \mathrm{~g} \mathrm{~N} \mathrm{~m}^{-2}$ at harvest (Fig. 4c), a value similar to the total immobilization of inorganic $\mathrm{N}$ by the other microorganisms (Fig. 4b).

\subsubsection{Predicting plant uptake and restitution of $N$}

The measured and predicted values of $\mathrm{N}$ stored in organs of the intercropping plants are shown in Fig. 5a for durum wheat and in Fig. $5 \mathrm{~b}$ for faba bean. The $\mathrm{N}$ stored in plants was considerably lower than organic $\mathrm{N}$ stored in soil compartments and was less than $\mathrm{N}$ stored in living microorganisms. The main part of the plant $\mathrm{N}$ was stored in the shoots: the shoot $\mathrm{N}$ in durum wheat corresponded to $4-24 \%$ of microbial $\mathrm{N}$, the shoot $\mathrm{N}$ in faba bean corresponded to $2-100 \%$ of microbial $\mathrm{N}$. The prediction of grain production of durum wheat and faba bean was significant at $\mathrm{p}<0.01$ (Table 2). The prediction of $\mathrm{N}$ in the other plant organs were inside the confidence intervals of the measured values (4 plot replicates $\times 4$ sampling replicates).

For both durum wheat and faba bean, the $\mathrm{N}$ remaining in the roots was about $10 \%$ of the $\mathrm{N}$ stored in the shoots (Fig. 4a and b). During
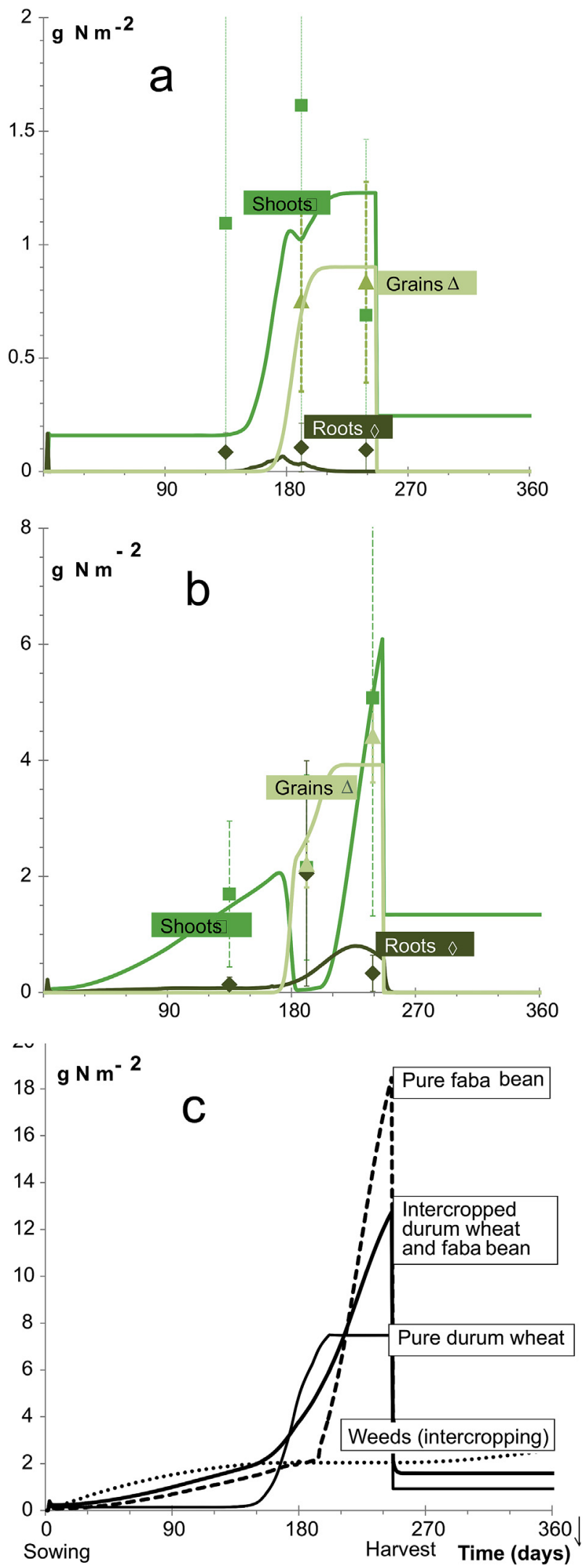

Fig. 5. N stocks in the plants: the measured stocks (green squares) with $95 \%$ confidence intervals and their predictions (green lines) in the plant shoots, plant roots (olive green diamonds and lines) and grains (yellow green triangles and lines) in the intercropping system, a) durum wheat organs, b) faba bean organs, c) total $\mathrm{N}$ stock in the plants (shoot + root + grains) of the intercropping compared to monoculture. (For interpretation of the references to colour in this figure legend, the reader is referred to the Web version of this 
Table 3

Specific parameters used to model the N cycle together with the C cycle (Ibrahim et al., 2016).

\begin{tabular}{|c|c|c|c|c|c|c|}
\hline \multirow[t]{2}{*}{ Function } & \multicolumn{2}{|c|}{ Parameter } & \multicolumn{4}{|l|}{ Crop } \\
\hline & Symbol & Description & Unit & Wheat $^{\mathrm{a}}$ & Faba bean $^{\mathrm{a}}$ & Intercrop ${ }^{\mathrm{b}}$ \\
\hline \multirow{3}{*}{$\begin{array}{l}\text { Plant N parameters } \\
j \in[\text { Durum wheat }]\end{array}$} & \multirow{3}{*}{$\begin{array}{l}\tau_{\mathrm{NRA}}^{j} \\
\tau_{\mathrm{NRS}}^{j} \\
\tau_{\mathrm{AG}}^{j}\end{array}$} & Root $\mathrm{N}$ absorption rate & $\mathrm{g}^{-1} \operatorname{root} \mathrm{C} \mathrm{d}^{-1}$ & 0.0121 & & 0.0044 \\
\hline & & $\mathrm{N}$ allocation rate to shoots & $d^{-1}$ & 0.331 & & 1 \\
\hline & & $\mathrm{N}$ transfer rate to grains & $d^{-1}$ & 0.0106 & & 0.0118 \\
\hline \multirow[t]{5}{*}{$j \in[$ Faba bean $]$} & \multirow{5}{*}{$\begin{array}{l}\tau_{\mathrm{NRA}}^{j} \\
\tau_{\mathrm{NRS}}^{j} \\
\tau_{\mathrm{AG}}^{j} \\
\tau_{\mathrm{NNF}}^{j} \\
\tau_{\mathrm{NNR}}^{j}\end{array}$} & Root $\mathrm{N}$ absorption rate & \multicolumn{2}{|l|}{$\mathrm{g}^{-1}$ root $\mathrm{C} \mathrm{d}^{-1}$} & 0.0212 & 0.0185 \\
\hline & & $\mathrm{N}$ allocation rate to shoots & \multicolumn{2}{|l|}{$d^{-1}$} & 0.243 & 0.2135 \\
\hline & & $\mathrm{N}$ transfer rate to grains & \multicolumn{2}{|l|}{$d^{-1}$} & 0.728 & 1 \\
\hline & & Nodule $\mathrm{N}$ fixation rate & \multicolumn{2}{|l|}{$\mathrm{g}^{-1} \mathrm{~N} \mathrm{~d}^{-1}$} & 0.0078 & 0.0108 \\
\hline & & $\mathrm{N}$ transfer rate from nodules to root & \multicolumn{2}{|l|}{$\mathrm{d}^{-1}$} & 1 & 1 \\
\hline $\mathrm{N}$ losses & $\tau_{\text {Nloss }}$ & Rate of losses of inorganic $\mathrm{N}$ & $\mathrm{d}^{-1}$ & 0.0024 & 0.0012 & 0.0024 \\
\hline \multirow[t]{2}{*}{$\mathrm{C}: \mathrm{N}$ ratios } & \multirow{2}{*}{$\begin{array}{l}\eta_{\mathrm{MB}}^{\lim } \\
\eta_{\mathrm{HS}}\end{array}$} & MB C:N threshold ratio for mineralization/immobilization & - & 9.87 & 11.24 & 9.87 \\
\hline & & Initial stable humus C:N ratio & - & 8.38 & 8.14 & 9.11 \\
\hline \multirow{4}{*}{$\begin{array}{l}\text { Time function for } \mathrm{N} \text { root absorption } \\
f_{4}^{j}\left(t, \tau_{\mathrm{NRA}}^{j}\right) j \in[\text { cereal }] \\
j \in[\text { legume }]\end{array}$} & \multirow{2}{*}{$\begin{array}{l}t_{\mathrm{NRA}}^{j} \\
\delta t_{\mathrm{NRA}}^{j}\end{array}$} & Optimal time for cereal $\mathrm{N}$ root absorption & d & \multicolumn{2}{|l|}{174.8} & 174.8 \\
\hline & & Deviation time for cereal $\mathrm{N}$ root absorption & \multicolumn{2}{|r|}{0.068} & & 0.068 \\
\hline & $t_{\mathrm{NRA}}^{j}$ & Optimal time for legume $\mathrm{N}$ root absorption & $\mathrm{d}$ & & 225.1 & 225.1 \\
\hline & $\delta t_{\mathrm{NRA}}^{j}$ & Deviation time for legume $\mathrm{N}$ root absorption & \multicolumn{2}{|l|}{$\mathrm{d}$} & 0.042 & 0.042 \\
\hline
\end{tabular}

\footnotetext{
${ }^{\text {a }}$ Plant $j$ in pure cropping.

b Plant $j$ in intercropping.
}

grain formation $\mathrm{N}$ stock was transferred to the grains, which gave a temporary decrease of $\mathrm{N}$ in other aerial parts, especially for faba bean (Fig. 5b)

Fig. $5 \mathrm{c}$ shows storage of $\mathrm{N}$ in plants of about $19 \mathrm{~g} \mathrm{~N} \mathrm{~m}^{-2}$ for pure faba bean, $13 \mathrm{~g} \mathrm{~N} \mathrm{~m}^{-2}$ for intercropping, and $7 \mathrm{~g} \mathrm{~N} \mathrm{~m}^{-2}$ for pure durum wheat, in inverse order of C production (Ibrahim et al., 2016) in these poor fertile plots.

\subsection{The $N$ flow parameters}

All parameters of Table 3 have been optimized together by the Powell's gradient method for the best prediction of the measured state variables (see 3.1. above). Available inorganic $\mathrm{N}$ was continuously regulated by the threshold $\eta_{M B}^{\lim }$ for its exchanges with MB when its adsorption by living roots was regulated by the rates $\tau_{\mathrm{NRA}}^{j}$ and the time functions $f_{4}^{j}$ related to physiological requirements of each plant $j$,. The other parameters essential for environmental exchanges where $\eta_{\mathrm{HS}}$ controlling the amount of $\mathrm{N}$ reserve into stable humus, $\tau_{\mathrm{NNF}}^{j}$ regulating rate of symbiotic fixation of atmospheric $\mathrm{N}$ and $\tau_{\text {Nloss }}$ regulating the whole losses of inorganic N. Other parameters of Table 3 regulate the $\mathrm{N}$ exchanges between plant organs, from roots to shoots, then from shoots to grains. The other parameters for $\mathrm{N}$ exchange remembered in Table 1 had been already optimised for $\mathrm{C}$ exchanges. The adjustment of Table 3 was found independent of initial values of the parameter set, indicating that the equation system was not over parameterized.

The maximum absorption of inorganic $\mathrm{N}$ was found at $175 \mathrm{~d}$ after sowing for durum wheat roots and $225 \mathrm{~d}$ after sowing for faba bean roots (Table 3). The cereal $\mathrm{N}$ stock was lower than for legume and the $\mathrm{N}$ seemed to be transferred more quickly from roots to shoots (Fig. 5a and b). Conversely, the legume shoots contain larger amounts of $\mathrm{N}$ than cereals, probably due to the quick transfer from the rhizobia and roots. In the early days of grain formation, the $\mathrm{N}$ grain source was shoot $\mathrm{N}$, root absorption of $\mathrm{N}$ only reaching a peak in the second stage of grain formation (Fig. 5b). The development of the durum wheat grains occurred before $\mathrm{N}$ release by mineralization of dead nodules and roots of the faba bean (Fig. 5b). In these conditions, most of the mineralized $\mathrm{N}$ was stored again in the legume organs (Fig. 5c), and did not benefit cereal production.

The $\mathrm{N}$ absorption rate for roots was lower for cereal than for legume (Table 3), but must be multiplied by the root biomass or root $\mathrm{C}$ to give the total absorption. It might be better to use the specific root surface but Shi et al. (2013) considered that it was better to correlate the root $\mathrm{N}$ uptake with the root mass, here assimilated to root C in Eq. (9), as the cereal root system is able to explore a much larger soil domain than legume roots (Ibrahim et al., 2016). The rates of $\mathrm{N}$ absorption by roots of cereal and legume, were found greater in pure cropping than in intercropping where available $\mathrm{N}$ was limited (Fig. 5a), and the sum of root absorption rates of cereal and legume in intercropping was found equal to the root absorption rate of pure cropped legumes.

The $\mathrm{N}$ allocation rate to shoots was greater for cereal than for legume. From Table 3, all $\mathrm{N}$ daily assimilated by roots of durum wheat was transferred to shoots in intercropping when $1 / 3$ was transferred in pure wheat cropping, illustrating a great $\mathrm{N}$ demand of the early flowering cereal in competition with the legume not satisfied by $\mathrm{N}$ transfer from faba-bean. In contrast, the $\mathrm{N}$ stock and biomass in the shoots were greater for faba bean (Fig. 5b) than for durum wheat (Fig. 5a), probably owing to $\mathrm{N}$ fixation, and a lower root absorption rate for cereal than for legume. Nevertheless, the $\mathrm{N}$ transfer rate to grains was lower for cereal than for legume (Table 3), again probably owing to a difference between the physiological properties of the cereals and the legumes. In the 1st phase of grain formation, the $\mathrm{N}$ transfer from shoots to grains was higher for faba bean (Fig. 5b) than for durum wheat (Fig. 5a). The peak $\mathrm{N}$ requirement for grain growth of cereal corresponded to the peak value of the predicted $\mathrm{N}$ in the roots (Fig. $5 \mathrm{a}$ ) and the $\mathrm{N}$ absorbed by roots was predicted as being transferred more quickly for grain growth in cereal than in legume and being stored temporarily in shoots for a shorter time for cereal than for legume.

The fixation rate $\tau_{\mathrm{NNF}}$ of atmospheric $\mathrm{N}_{2}$ was close to $10 \mathrm{mg} \mathrm{N} \mathrm{g}^{-1}$ nod C per day being slightly higher in intercropping than for pure legumes (Table 3), and corresponded to a total fixation of $9 \mathrm{~g} \mathrm{~N} \mathrm{~m}^{-2}$ for the entire cycle (Fig. 4c). This experiment showed that the $\tau_{\mathrm{NNR}}$ parameter regulating the $\mathrm{N}$ transfer rate from nodules to roots can be removed from the model because the best-fit value was 1 (the maximum value) in both intercropping and pure legume cropping. Each day, all 
the $\mathrm{N}_{2}$ that had been fixed was transferred to the legume roots, then some was transferred to the legume shoots and grains, and some transferred to soil microorganisms by root mortality (perhaps including exudation), which was found to be ten times higher for faba bean than for durum wheat by Ibrahim et al. (2016).

The threshold $\eta_{M B}^{\lim }$ of the $\mathrm{C}: \mathrm{N}$ ratio for microorganisms is the most important parameter for regulating $\mathrm{N}$ mineralization or immobilization (Fig. 3b). In this work, in a well-drained system on a plain, microorganism homeostasis was a plausible assumption (Pansu et al., 2014). Net immobilization of inorganic $\mathrm{N}$ was predicted when the daily calculated MB C:N ratio was greater than the threshold value of 9.87 in intercropping (Table 3), otherwise, there was net $\mathrm{N}$ mineralization. The threshold value was found slightly higher in pure cropping of faba bean than in intercropping, corresponding to higher $\mathrm{N}$ mineralization in intercropping. The initial stable humus $\mathrm{C}: \mathrm{N}$ ratio $\eta_{\mathrm{HS}}$ was 9.11 (Table 3 ), which indicates a high reserve of stable organic $\mathrm{N}$, not available at short term for plants, in this soil.

The rate for $\mathrm{N}$ losses from the intercropping system $\tau_{\text {Nloss }}$ was estimated at $0.24 \%$ of inorganic $\mathrm{N}$ per day (Table 3 ) which estimates the total losses of $2 \mathrm{~g} \mathrm{~N} \mathrm{~m}^{-2}$ close to the amount of $\mathrm{N}$ measured in the weeds after hand weeding $150 \mathrm{~d}$ after sowing. In this system, therefore, the $\mathrm{N}$ loss during intercropping was taken to be the $\mathrm{N}$ stored in weeds, no supplementary $\mathrm{N}$ losses to the atmosphere and groundwater was detected.

\section{Discussion}

\subsection{Robustness and parsimony of the model}

All parameter values and relationships previously obtained with ${ }^{14} \mathrm{C}$ isotopic tracers for calibration in two contrasted mountain ecosystems of Venezuela and Bolivia, and validation in 6 very different Venezuelan ecosystems (Pansu et al., 2010) were retained in this study. This study confirms the result of Pansu et al. (2014) based on simultaneous ${ }^{14} \mathrm{C}$ and ${ }^{15} \mathrm{~N}$ transfers: the $\mathrm{N}$ cycle can be predicted in close association with the $\mathrm{C}$ cycle by computing the mineralization or immobilization exchanges between inorganic $\mathrm{N}$ and microorganisms. It illustrates the robustness of the model calibrated and validated in various acidic tropical conditions, applied here to calcareous Mediterranean conditions, using the same set of equations and parameters linking environmental variables to microbial functions. Apart $\eta_{M B}^{\lim }$ the $\mathrm{N}$ exchange parameter between MB and inorganic N (Eq. (8)), MOMOS does not include parameters unrelated to temperature and moisture, such as the efficiency factors often used in other models. Of published models, it could be the most sensitive to climate change and the most parsimonious (Ockham's razor, lex parsimoniae), in terms of definition of its equations and parameters. The number and diversity of sites where was applied the microbial part of the model regulating the OM transformations in soil authorize to retain the equation system of Pansu et al. (2010, 2014). The parameter $\eta_{\mathrm{HS}}$ regulates the higher storage of organic $\mathrm{N}$ but only in the stable HS compartment which can sustain the life at long term but is not available at short term for crops. Here it is optimized conjointly with the other parameters but measurement methods could be also developed (Pansu and Gautheyrou, 2006) for storage in soil databases.

The eco-physiological parameters additionally defined for predicting $C$ transfer between plant organs, microorganisms, the soil and the atmosphere, in this intercropping system (Ibrahim et al., 2016) were also retained for $\mathrm{N}$ modelling. But in contrast with the well-tested decomposition model, this plant module is probably improvable, considering more deeply the mechanisms regulating photosynthesis and plant growth, as it is sometimes considered in crop models. Nevertheless, this module enables to predict accurately all the state variables measured at different growth stages in the intercropping system. As transfer parameters optimized by the equation system are often hard to measure experimentally, we propose these equations as a collecting method in various conditions. The eventual improvements will be linked to measurements of new state variables regulating the $\mathrm{C}$ and $\mathrm{N}$ transfers but will take care to avoid an immoderate increase of the number of parameters in order to prevent over parameterization and to preserve the convergence toward unique parameter sets. Decomposers and rhizobia were sufficient for predicting the entire data set of this system, neglecting at this time other possible transfers of $\mathrm{N}$ through arbuscular mycorrhiza (Chalk et al., 2006). Equations (9)-(14) are available for all systems of cropping, prairie or fallows with any number of plant $j$ growing simultaneously. Nevertheless, they are not tested to describe the aerial and root production of necromass of forest systems, where the state variables of living trees are more difficult to measure but can be estimated by the forest production models.

\section{2. $C$ and $N$ flows and yield of the intercropping system}

The key to optimizing crop production by using ecological mechanisms will be to adjust the plant $\mathrm{N}$ demand linked to $\mathrm{C}$ photosynthesis, and microbial production of inorganic $\mathrm{N}$ linked to the $\mathrm{C}$ availability for microorganisms. In the intercropping example of this study:

(1) The amount of $\mathrm{C}$ and $\mathrm{N}$ in the organic compartments of microbial origin represent the principal reserves in soil, the stable humus HS is the largest reserve which can sustain a latent slow functioning of living organisms; in contrast the labile humus compartment HL is the main stock of potentially available $\mathrm{N}$ at short term for cropping's yields;

(2) Living organisms store much less $\mathrm{C}$ and $\mathrm{N}$ than humus with a higher reserve in microorganisms than in plants. In this study, the decomposer microorganisms immobilized the soil inorganic $\mathrm{N}$ in the first 6 months after sowing, then mineralized $\mathrm{N}$ when the substrate plant debris increased. The two inorganic $\mathrm{N}$ values higher than model predictions can be not only inorganic $\mathrm{N}$; in this unfertilized soil, the $\mathrm{K}_{2} \mathrm{SO}_{4}$ extracts can contain a part of organic $\mathrm{N}$ forms (anonymous reviewer, personal communication). In addition, wet soil samples could be insufficiently preserved by storage at $4{ }^{\circ} \mathrm{C}$ and a slight microbial mineralization could induce a slight overestimation of the measured data explaining the model underestimation. Atmospheric $\mathrm{N}$ fixing by symbiotic microorganisms was predicted as being at its peak from 90 to 180 days after sowing. The total fixed $\mathrm{N}$ was equivalent to total $\mathrm{N}$ immobilization during intercropping; This rate was not measured but introduced as a plausible value before adjusting $\tau_{\mathrm{NNF}}$, otherwise the best fit $\tau_{\mathrm{NNF}}$ overestimated the $\mathrm{N}$ fixation (near $40 \mathrm{~g} \mathrm{~N} \mathrm{~m}^{-2}$ ) compared to most of literature data (Larue and Patterson, 1981). $\mathrm{N}$ fixation in Canadian soils was estimated in the range $5-30 \mathrm{~g} \mathrm{~N} \mathrm{~m}^{-2}\left(50-300 \mathrm{~kg} \mathrm{~N} \mathrm{ha}^{-1}\right)$ depending on the legume species (Yang et al., 2010) excluding faba bean. López-Bellido et al. (2006) estimated the N fixed by faba bean in rotation with cereals in the range 3.9-14.4 $\mathrm{g} \mathrm{N} \mathrm{m}^{-2}$. Jensen et al. (2010) reported that faba bean had the highest average reliance on $\mathrm{N}_{2}$ fixation and could save up to $10-20 \mathrm{~g} \mathrm{~N} \mathrm{~m}^{-2}$ in the amount of $\mathrm{N}$ fertilizer required to maximize the yield of crops grown after faba bean. Additionally, it is well documented that phosphorous availability influences the nodule development and $\mathrm{N}$ fixation (e.g. Kouas et al., 2005). The experimental plots of this paper were not fertilized for 13 years but we have observed well developed symbiotic nodules during plant preparation, which could explain a relatively high N fixation. For Alkama et al. (2009), the nitrogenase activity can induce local dissolution of $\mathrm{P}$ by acidification of root tips favoring $\mathrm{P}$ uptake and genesis of new symbiotic nodules on the root hairs. It could be very interesting to extend MOMOS to model the exchanges of inorganic $\mathrm{P}$ with the microorganisms, conjointly with the exchanges of N. Further experiments are also required to check whether the above equations of this paper constitute a reliable method for quantifying $\mathrm{N}$ fixation. It should be checked against 
other methods, often using ${ }^{15} \mathrm{~N}$ measurement (Warembourg, 1993); Chalk and Ladha, 1999) which can be expensive to implement.

(3) Ibrahim et al. (2016) showed that the photosynthetic C flows were different for cereals and legumes. According to Trapeznikov et al. (2003), root C of wheat was more developed in poor fertile soils. Cereals mobilized $\mathrm{C}$ for root growth to find nutrients with relatively low root mortality (Table 1 ) but a high loss of $\mathrm{C}$ by root respiration (Ibrahim et al., 2016), probably the energy source for growth (Amthor, 2000). The loss of $\mathrm{C}$ by root respiration of cereal was much greater than for legume but the transfers of $\mathrm{C}$ and $\mathrm{N}$ to soil microorganisms by root mortality were largely lower for cereal than for legume (Table 1). The $\mathrm{C}$ use efficiency by microorganisms, continuously modelled from all the $\mathrm{C}$ inputs minus the $\mathrm{C}$ outputs of $\mathrm{MB}$, was found always lower to 0.2 and decreasing (but not significantly) with increasing of the C:N ratio modelled for these inputs as shown for data of Manzoni (2017).

(4) From Ibrahim et al. (2016), intercropping did not increase the total C production in the two plants which was lower than for pure durum wheat in this poor fertile system, contradicting Fujita et al. (1992) but agreeing with the wheat/faba bean intercropping results of Fan et al. (2006). Ibrahim et al. (2016) found optimal times for grain growth of $182 \mathrm{~d}$ for durum wheat and $191 \mathrm{~d}$ for faba bean, both lower than optimal times of absorption of inorganic $\mathrm{N}$ by roots, The durum wheat (Triticum durum) cultivar LA1823 needs most inorganic $\mathrm{N}$ just before grain formation at 150-180 d after sowing (Fig. 5a). The developed root system of durum wheat must find inorganic $\mathrm{N}$ by soil exploration. At this time the inorganic $\mathrm{N}$ was mainly fixed and stored in the legume shoots and grains (Fig. 4b) and latter was transferred to decomposer microorganisms which mineralize inorganic N (Fig.4b) too late for the cereal requirement.

\section{Conclusion}

Overall these results show that the main objectives of the introduction section are attained. The general equation system for decomposition previously proposed then validated in various tropical ecosystems appears again valid in alkaline Mediterranean conditions, just after replacement of tropical variables by the new local variables for weather, soil and qualities of inputs from plants. The extension of the decomposition part of the model at regional scale, need only to collect climate data and data on soil texture (fine $0-20 \mu \mathrm{m}$ fraction) or soil $\mathrm{pH}$, and soil water retention, using the optimal values and relationships given in Pansu et al. (2010, 2014). The equation system added to this paper for $\mathrm{N}$ transfers through plants and symbiosis appears well complementary of those previously used for $\mathrm{C}$ in the same experiment. Though probably improvable in mechanistic terms, it enables to optimize a set of parameter values not depending on initial values. Thus it appears not over parameterized and is now available for use in any agro-ecological system, using if possible the simplifying hypothesis of microbial homeostasis which is found valid in this work, or the more complex hypothesis of decomposer chain (Pansu et al., 2014). This paper and that of Ibrahim et al. (2016) can be used to give first approximation of transfer rates between plant organs in order to extend the model at regional scales.

Other approximations can be extracted from literature data or from experiments analogous to this work, but with other plant covers. Such combinations of data collection and modelling appear as tools to compare and improve parameters of vegetal production in agroecology. Concerning the microbial action on improvement or depletion of the plant growth of this study, the results showed that this vary depending on the phenological stage. During the first six months after seedling, the larger part of inorganic $\mathrm{N}$ was immobilized by microorganisms; plants did not take up a great part of inorganic $\mathrm{N}$ except atmospheric $\mathrm{N}_{2}$ for faba bean. After that, the decomposers began to mineralize inorganic $\mathrm{N}$ from the dead roots of legume which became available for plant growth, but too late to satisfy the great $\mathrm{N}$ requirement of the roots of durum wheat in this unfertilized system. Consequently, research to improve the intercropping of legumes and cereals should select associations of late-flowering cereals and/or earlyflowering legumes to improve use efficiency by the cereal roots of inorganic $\mathrm{N}$ resulting from decomposition of $\mathrm{N}$ rich legume debris. With the plant species of this experiment, the commonly used annual rotation of durum wheat and faba bean (Köpke and Nemecek, 2010; Jensen et al., 2010) must be preferred to intercropping. It should be optimized by complementary research using the modelling protocol to improve $\mathrm{C}$ use efficiency by minimizing respiration losses (Manzoni, 2017) and the $\mathrm{N}$ use efficiency (Fageria and Baligar, 2005) by avoiding possible losses of the potentially available $\mathrm{N}$ (inorganic $\mathrm{N}$ plus living organism $\mathrm{N}$ plus labile humus $\mathrm{N}$ ) between the legume and the cereal crops. The modelling protocol of this paper jointly to that of Ibrahim et al. (2016) appear as a new tool to study the $\mathrm{C}$ and $\mathrm{N}$ transfers and their relations in all cultivated and natural systems. Here, it was applied to two plants in intercropping in comparison with pure cropping, but the equations authorize transpositions to other systems with any number $j$ of associated plant species. The modelling method enables the simultaneous calculation of exchange parameters of great importance in plant physiology, by optimization against state variables of $\mathrm{C}$ and $\mathrm{N}$ stocks much more easy to collect than flow data. For example, it should be very interesting to extend the above study to a large panel of experiments comparing modelling results of different agricultural choices. If possible, to compare with other measurement methods of $\mathrm{N}$ and $\mathrm{C}$ flows (as isotope methods) in order to collect essential parameters such as growth rates of plants, allocation rates to plant organs, adsorption rates by roots, fixation rates by symbioses, or rates of losses for crops. And to attempt extending the studies to the modelling of the exchanges of phosphorous between the living organisms and the soil compartments.

This mechanistic modelling assigns to microbial decomposers their key role in linking the growth of the different plant species and symbioses in interaction. An experimental or bibliographic collecting of parameters defined in this paper conjointly with those of Ibrahim et al. (2016) and Pansu et al. (2010, 2014), see compilation in supplementary material annexed to this paper, will enable to set out a strong data base for controlling the $\mathrm{C}$ and $\mathrm{N}$ exchanges of the life at regional scale. Already recognised as generalizable for decomposition; the MOMOS model will be an invaluable tool of prediction of $\mathrm{C}$ and $\mathrm{N}$ transfers between microbe and plant organisms, which will greatly improve predictions of the reserves linked to the earth life and acting on climate change.

\section{Acknowledgements}

This work was part of the international program Fabatropimed supported by the Agropolis Fondation of Montpellier, France (program CfP 2010-GFP). The authors wish to thank Dominique Desclaux, Thierry Laporte, Bruno Lorentz and Alain Gil for their support at the INRA experimental station in Mauguio, (UE Diascope), Gérard Souche, Catherine Pernot, Odile Domergue and Manon Villeneuve (UMR Eco\& sols, Supagro, Cirad, Inra, IRD, for help in field sampling, Dr. Claire Marsden for help in measuring soil respiration, Jöele Toucet, Agnès Martin, Didier Brunet, Jean-Louis Aznard (UMR Eco\&sols), Bruno Buatois (Cefe-CNRS) for help in the microbial analyses and soil water retention measurements, Jean-Luc Marger (UPR Recyclage et Risque Cirad, for fiber fractionation of plant parts, Pr. Bernard Saugier (Paris sud Univ.), Pr. Bernard Nicolardot (Agrosup Dijon, Dr. Nathalie Fromin (Cefe-CNRS) and Dr. Christophe Jourdan (UMR Eco\&sols) for their help on plant eco-physiology and microbial ecology.

\section{Appendix A. Supplementary data}

Supplementary data related to this article can be found at https:// doi.org/10.1016/j.soilbio.2018.06.011. 


\section{References}

Alkama, N., Boulou Bi Bolou, E., Drevon, J.J., 2009. Genotypic variability in P use efficiency for symbiotic nitrogen fixation is associated with variation of proton efflux in cowpea rhizosphere. Soil Biol. Biochem. 41, 1814-1823.

Amthor, J.S., 2000. The McCree-de Wit-Penning de Vries-Thornley Respiration Paradigms: 30 Years Later. Ann. Bot. 86, 1-20. https://doi.org/10.1006/anbo.2000. 1175.

Blagodatsky, S., Blagodatskaya, E., Yuyukina, T., Kuzyakov, Y., 2010. Model of apparent and real priming effects: linking microbial activity with soil organic matter decomposition. Soil Biol. Biochem. 42, 1275-1283.

Brisson, N., Mary, B., Ripoche, D., Jeuffroy, M.H.,F.,R., Nicoullaud, B., Gate, P., DevienneBarret, F., Antonioletti, R., Durr, C., Richard, G., Baudoin, N., Recous, S., Tayot, X., Plenet, D., Cellier, P., Machet, J.M., Meynard, J.M., Delécolle, R., 1998. STICS: a generic model for the simulation of crops and their water and nitrogen balances. I. Theory and parametrization applied to wheat and corn. Agronomie 18, 311-346.

Brookes, P.C., Kragt, J.F., Powlson, D.S., Jenkinson, D.S., 1985. Chloroform fumigation and the release of soil nitrogen: the effects of fumigation time and temperature. Soil Biol. Biochem. 17, 831-835.

Chalk, P.M., Ladha, J.K., 1999. Estimation of legume symbiotic dependence: an evaluation of techniques based on 15N dilution. Soil Biol. Biochem. 31, 1901-1917. https:// doi.org/10.1016/S0038-0717(99)00095-4.

Chalk, P.M., Souza, R.d.F., Urquiaga, S., Alves, B.J.R., Boddey, R.M., 2006. The role of arbuscular mycorrhiza in legume symbiotic performance. Soil Biol. Biochem. 38, 2944-2951. https://doi.org/10.1016/j.soilbio.2006.05.005.

Corre-Hellou, G., Faure, M., Launay, M., Brisson, N., Crozat, Y., 2009. Adaptation of the STICS intercrop model to simulate crop growth and $\mathrm{N}$ accumulation in pea-barley intercrops. Field Crop. Res. 113, 72-81. https://doi.org/10.1016/j.fcr.2009.04.007.

Fageria, N.K., Baligar, V.C., 2005. Enhancing nitrogen use efficiency in crop plants. In: Donald, L.S. (Ed.), Advances in Agronomy. Academic Press, pp. 97-185.

Fan, F., Zhang, F., Song, Y., Sun, J., Bao, X., 2006. Nitrogen fixation of faba bean (Vicia faba L.) interacting with a non-legume in two contrasting intercropping systems. Plant Soil 283, 275-286.

Fujita, K., Ofosu-Budu, K.G., Ogata, S., 1992. Biological nitrogen fixation in mixed legume-cereal cropping systems. Plant Soil 141, 155-175.

Gärdenäs, A.I., Ågren, G.I., Bird, J.A., Clarholm, M., Hallin, S., Ineson, P., Kätterer, T., Knicker, H., Nilsson, S.I., Näsholm, T., Ogle, S., Paustian, K., Persson, T., Stendahl, J., 2011. Knowledge gaps in soil carbon and nitrogen interactions e from molecular to global scale. Soil Biol. Biochem. 43, 702-717.

Gras, A., Ginovart, M., Valls, J., Baveye, P.C., 2011. Individual-based modelling of carbon and nitrogen dynamics in soils: parameterization and sensitivity analysis of microbial components. Ecol. Model. 222, 1998-2010.

Hammoudi, A., Iosifescu, O., Bernoux, M., 2014. Mathematical analysis of a nonlinear model of soil carbon dynamics. Differential Equations and Dynamical Systems. https://doi.org/10.1007/s12591-014-0227-5.

Ibrahim, H., Pansu, M., Blavet, D., Hatira, A., McDonald, P., Bernoux, M., Drevon, J.-J., 2016. Modelling the continuous exchange of carbon between living organisms, the soil and the atmosphere. Plant Soil 398, 381-397. https://doi.org/10.1007/s11104015-2665-4.

Inselsbacher, E., Wanek, W., Strauss, J., Zechmeister-Boltenstern, S., Müller, C., 2013. A novel $15 \mathrm{~N}$ tracer model reveals: plant nitrate uptake governs nitrogen transformation rates in agricultural soils. Soil Biol. Biochem. 57, 301-310.

Jensen, E.S., Peoples, M.B., Hauggaard-Nielsen, H., 2010. Faba bean in cropping systems. Field Crop. Res. 115, 203-216. https://doi.org/10.1016/j.fcr.2009.10.008.

Jetten, M.S., 2008. The microbial nitrogen cycle. Environ. Microbiol. 10, 2903-2909. https://doi.org/10.1111/j.1462-2920.2008.01786. x EMI1786 [pii].

Joergensen, R.G., Mueller, T., 1996. The fumigation-extraction method to estimate soil microbial biomass: calibration of the k(EN) value. Soil Biol. Biochem. 28, 33-37.

Kaboré, W.T., Pansu, M., Hien, E., Brunet, D., Barthès, B.G., Houot, S., Coulibaly, A., Zombré, P., Thuriès, L., Masse, D., 2012. Near infrared reflectance spectroscopy applied to model the transformation of added organic materials in soil. J. Near Infrared Spectrosc. 20, 339-351.

Köpke, U., Nemecek, T., 2010. Ecological services of faba bean. Field Crop. Res. 115, 217-233. https://doi.org/10.1016/j.fcr.2009.10.012.

Kouas, S., Labidi, N., Debez, A., Abdelly, C., 2005. Effect of P on nodule formation and N fixation in bean. Agron. Sustain. Dev. 25, 389-393.

Larue, T.A., Patterson, T.G., 1981. How much nitrogen do legumes fix? In: Brady, N.C. (Ed.), Advances in Agronomy. Academic Press, pp. 15-38.

Lin, B.-L., Sakoda, A., Shibasaki, R., Goto, N., Suzuki, M., 2000. Modelling a global biogeochemical nitrogen cycle in terrestrial ecosystems. Ecol. Model. 135, 89-110.

López-Bellido, L., López-Bellido, R.J., Redondo, R.,J.,B., 2006. Faba bean nitrogen fixation in a wheat-based rotation under rainfed Mediterranean conditions: effect of tillage system. Field Crop. Res. 98, 253-260. https://doi.org/10.1016/j.fcr.2006.03. 001.

Manzoni, S., 2017. Flexible carbon-use efficiency across litter types and during decomposition partly compensates nutrient imbalances-results from analytical stoichiometric models. Front. Microbiol. 8, 661. https://doi.org/10.3389/fmicb.2017.00661.

Manzoni, S., Porporato, A., 2009. Soil carbon and nitrogen mineralization: theory and models across scales. Soil Biol. Biochem. 41, 1355-1379.

Morell, F.J., Whitmore, A.P., Álvaro-Fuentes, J., Lampurlanés, J., Cantero-Martínez, C., 2012. Root respiration of barley in a semiarid Mediterranean agroecosystem: field and modelling approaches. Plant Soil 351, 135-147. https://doi.org/10.1007/ s11104-011-0938-0.

Neill, C., Gignoux, J., 2006. Soil organic matter decomposition driven by microbial growth: a simple model for a complex network of interactions. Soil Biology \& Biochemistry 38, 803-811.

Pansu, M., Bottner, P., Sarmiento, L., 2009. Micro-Organismes et Matière Organique du Sol (modèle MOMOS): bilan de 20 ans de modélisation basée sur le traçage isotopique in situ. Étude Gestion Sols 16, 213-232.

Pansu, M., Gautheyrou, J., 2006. Handbook of Soil Analysis - Mineralogical, Organic and Inorganic Methods. Springer, Berlin, Heidelberg, New-York.

Pansu, M., Machado, D., Bottner, P., Sarmiento, L., 2014. Modelling microbial exchanges between forms of soil nitrogen in contrasting ecosystems. Biogeosciences 11, 915-927. https://doi.org/10.5194/bg-11-915-2014.

Pansu, M., Sarmiento, L., Rujano, M.A., Ablan, M., Acevedo, D., Bottner, P., 2010. Modeling Organic transformations by Micro-Organisms of Soils in six contrasting ecosystems: validation of the MOMOS model. Global Biogeochem. Cycles 24, GB1008. https://doi.org/10.1029/2009GB003527.

Pansu, M., Thuriès, L., Soares, M.L., Simöes, V.L., Martin Neto, L., 2017. Modelling the transformation of organic materials in soil with nuclear magnetic resonance spectra. Eur. J. Soil Sci. 68, 90-104.

Penning de Vries, F.W.T., Jansen, D.M., ten Berge, H.F.M., Bakema, A., 1989. Simulation of Ecophysiological Processes of Growth in Several Annual Crops. Pudoc, Wageningen.

Philippot, L., Spor, A., Hénault, C., Bru, D., Bizouard, F., Jones, C.M., Sarr, A., Maron, P.A., 2013. Loss in microbial diversity affects nitrogen cycling in soil. The ISME Journal, International Society for Microbial Ecology 13, 1609-1619.

Ritchie, J.T., Otter, S., 1984. In: Laboratory, U.-A.-S.G.S.a.W.R. (Ed.), Description and Performance of CERES-Wheat, a User-oriented Wheat Yield Model, pp. 159-175 Temple, TX.

Sikorski, J., 2015. The prokaryotic biology of soil. Soil organisms 87, 1-28.

Shi, J., Ben-Gal, A., Yermiyahu, U., Wang, L., Zuo, Q., 2013. Characterizing root nitrogen uptake of wheat to simulate soil nitrogen dynamics. Plant Soil 363, 139-155. https:// doi.org/10.1007/s11104-012-1299-z.

Thuriès, L., Pansu, M., Larré-Larrouy, M.C., Feller, C., 2002. Biochemical composition and mineralization kinetics of organic inputs in a sandy soil. Soil Biol. Biochem. 34, 239-250.

Todd-Brown, K.E.O., Hopkins, F.M., Kivlin, S.N., Talbot, J.M., Allison, S.D., 2012. A framework for representing microbial decomposition in coupled climate models. Biogeochemistry 109, 19-33. https://doi.org/10.1007/s10533-011-9635-6.

Trapeznikov, V.K., Ivanov, I.I., Kudoyarova, G.R., 2003. Effect of heterogeneous distribution of nutrients on root growth, ABA content and drought resistance of wheat plants. Plant Soil 252, 207-214.

Unkovich, M., Baldock, J., 2008. Measurement of asymbiotic N2 fixation in Australian agriculture. Soil Biol. Biochem. 40, 2915-2921.

Vance, E.D., Brookes, P.C., Jenkinson, D.S., 1987. An extraction method for measuring soil microbial biomass C. Soil Biol. Biochem. 19, 703-707.

van der Heijden, M.G.A., Bardgett, R.D., van Straalen, N.M., 2008. The unseen majority: soil microbes as drivers of plant diversity and productivity in terrestrial ecosystems. Ecol, Lett. 11, 296-310.

Verberne, E.L., Hassink, J., De Willigen, P., Groot, J.J.R., Van Veen, J.A., 1990. Modelling organic matter dynamics in different soils. Netherland journal of Agricultural Science $38,221-238$.

Warembourg, F.R., 1993. 5-Nitrogen fixation in soil and plant systems. In: Roger, K., Eldor, A.P., Jerry, M., Henry BlackburnA2-Roger Knowles, E.A.P.J.M., Henry, B. (Eds.), Nitrogen Isotope Techniques. Academic Press, San Diego, pp. 127-156.

Williams, J.R., Jones, C.A., Kiniry, J.R., Spanel, D.A., 1989. The EPIC crop growth model. Transactions of the ASAE 32, 497-511.

Wu, H., Dannenmann, M., Wolf, B., Han, X.G., Zheng, X., Butterbach-Bahl, K., 2012. Seasonality of soil microbial nitrogen turnover in continental steppe soils of Inner Mongolia. Ecosphere 3 (34), 1-18. https://doi.org/10.1890/ES11-00188.

Yang, J.Y., Drury, C.F., Yang, X.M., De Jong, R., Huffman, E.C., Campbell, C.A., Kirkwood, V., 2010. Estimating biological N2 fixation in Canadian agricultural land using legume yields. Agric. Ecosyst. Environ. 137, 192-201. 